\title{
Grazing Incidence Liquid Metal Mirrors (GILMM) as the Final Optics for Laser Inertial Fusion Energy Power Plants
}

R. W. Moir

June 25, 1999

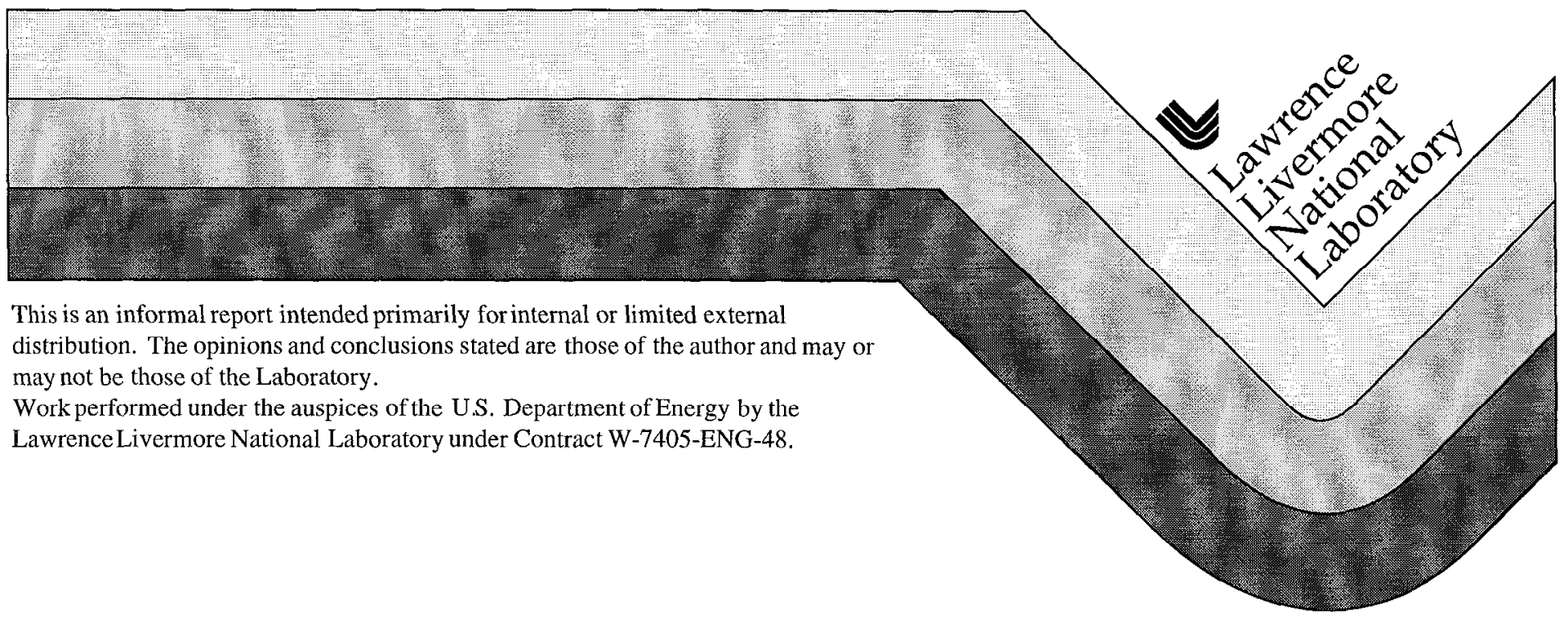




\section{DISCLAIMER}

This document was prepared as an account of work sponsored by an agency of the United States Government. Neither the United States Government nor the University of California nor any of their employees, makes any warranty, express or implied, or assumes any legal liability or responsibility for the accuracy, completeness, or usefulness of any information, apparatus, product, or process disclosed, or represents that its use would not infringe privately owned rights. Reference herein to any specific commercial product, process, or service by trade name, trademark, manufacturer, or otherwise, does not necessarily constitute or imply its endorsement, recommendation, or favoring by the United States Government or the University of California. The views and opinions of authors expressed herein do not necessarily state or reflect those of the United States Government or the University of California, and shall not be used for advertising or product endorsement purposes.

This report has been reproduced directly from the best available copy.

Available to DOE and DOE contractors from the

Office of Scientific and Technical Information

P.O. Box 62, Oak Ridge, TN 37831

Prices available from (423) 576-8401

Available to the public from the

National Technical Information Service

U.S. Department of Commerce

5285 Port Royal Rd.,

Springfield, VA 22161 
Grazing incidence liquid metal mirrors (GILMM) as the final optics for laser inertial fusion energy power plants

R. W. Moir

\section{Abstract}

A thin film of liquid metal serves as a grazing incident liquid metal mirror (GILMM) for robust final optics of an inertial fusion energy (IFE) power plant. The amount of laser light the mirror can withstand, called the damage limit, of a sodium film $85^{\circ}$ from normal arbitrarily set by surface temperature rise of $200^{\circ} \mathrm{C}$ to limit liquid ablation is $57 \mathrm{~J} / \mathrm{cm}^{2}$ normal to the beam for a $20 \mathrm{~ns}$ pulse and 1.3 $\mathrm{J} / \mathrm{cm}^{2}$ for a 10 ps pulse of $0.35 \mu \mathrm{m}$ light. Liquid aluminum can handle $106 \mathrm{~J} / \mathrm{cm}^{2}$. The damage limit actually should be set by avoiding liquid ablation due to the rapid surface heating which is expected to result in even higher temperatures rises than $200{ }^{\circ} \mathrm{C}$ and even higher power densities. The liquid surface is kept flat to the required accuracy by a combination of polished substrate, adaptive optics, surface tension and low Reynolds number, laminar flow in the film. The film's substrate must be polished to $\pm 0.015 \mu \mathrm{m}$. Then surface tension keeps the surface smooth over short distances $(<10 \mathrm{~mm})$ and low Reynolds number laminar flow keeps the surface smooth by keeping the film thickness constant to less than \pm $0.01 \mu \mathrm{m}$ over long distance $>10 \mathrm{~mm}$. Adaptive (deformable) optics techniques keep the substrate flat to within $\pm 0.06 \mu \mathrm{m}$ over $100 \mathrm{~mm}$ distance and $\pm 0.6 \mu \mathrm{m}$ over $1000 \mathrm{~mm}$ distances. The mirror can withstand the $\mathrm{x}$-ray pulse when located $30 \mathrm{~m}$ away from the microexplosions of nominal yield of $400 \mathrm{MJ}$ (50 MJ x rays) when $\mathrm{Li}$ is used but for higher atomic number liquids like $\mathrm{Na}$ and $\mathrm{Al}$ there may be too high a temperature rise forcing use of other x-ray attenuation methods such as xenon gas, which may be needed for first wall protecting anyway. The cumulative damage from neutrons causing warpage of the liquid film's substrate can be compensated by adaptive optics techniques giving the mirrors long life, perhaps 30 years. The GILMM should be applicable to both direct and indirect drive and pulse lengths appropriate to slow compression ( 20 ns) or fast ignition $(\sim 10 \mathrm{ps})$. Experiments are discussed to verify the predicted damage limit and required smoothness. 
Table of contents

Introduction 3

System layout $\quad 4$

Damage limit theory $\quad 7$

Candidate liquids $\quad 8$

$\begin{array}{ll}\text { Optical penetration and sound travel time effects } & 13\end{array}$

Theoretical basis for smooth film flow 14

$\begin{array}{ll}\text { Stability of the flowing film } & 17\end{array}$

Required smoothness of the liquid film and metal substrate 24

Flow rate control $\quad 26$

Meniscus effects $\quad 26$

Variation in surface tension and viscosity with temperature effects $\quad 27$

Design of cooling system 28

$\begin{array}{ll}\text { Vibration damping system } & 29\end{array}$

Energy in vibrations $\quad 30$

Active pointing system

Differential heating 31

Dry out $\quad 31$

Neutron effects $\quad 32$

X-ray effects $\quad 33$

Debris protection $\quad 34$

X-ray protection by gas $\quad 35$

Blast effect on mirror deflection and mitigation $\quad 35$

Optical alignment $\quad 36$

Experimental test apparatus $\quad 36$

Conclusion $\quad 37$

Acknowledgments $\quad 37$

References $\quad 38$ 


\section{Introduction}

Metal mirrors have long been used in optics but for wavelengths of interest for laser IFE of 0.25 to $0.35 \mu \mathrm{m}$, grazing incidence $\left(\approx 85^{\circ}\right.$ to normal) is needed to reduce absorption. Bieri analyzed a grazing incidence metal mirror (GIMM) and found aluminum could handle $18 \mathrm{~J} / \mathrm{cm}^{2}$ normal to the beam which is $1.5 \mathrm{~J} / \mathrm{cm}^{2}$ on the film ${ }^{1}$. His design was used for the Prometheus ${ }^{2}$ (Fig. 1) and Sombrero ${ }^{3}$ (Fig. 2) laser IFE power plants studies. Sombrero had mirrors at $6^{\circ}$ grazing at 30 $\mathrm{m}$ of normal cross section of $1 \mathrm{~m} \times 0.43 \mathrm{~m}$ with a mirror $1 \mathrm{~m}$ wide and $4.1 \mathrm{~m}$ along the slope direction. There were 60 beams totaling $3.6 \mathrm{MJ}$ or $60 \mathrm{~kJ} / \mathrm{beam}$. The $60 \mathrm{~kJ}$ over $4.1 \mathrm{~m}^{2}$ gave an intensity of $1.5 \mathrm{~J} / \mathrm{cm}^{2}$ on the film $\left(14 \mathrm{~J} / \mathrm{cm}^{2}\right.$ normal to the beam). At $50 \mathrm{~m}$, the distance to the first conventional optics, the $14 \mathrm{~J} / \mathrm{cm}^{2}$ drops to $5 \mathrm{~J} / \mathrm{cm}^{2}$ damage limit on this conventional optics. A problem however, with the designs is that flaws as small as $\sim 1 \mu \mathrm{m}$ "looks" locally like normal incidence $\left(\sim 14 \mathrm{~J} / \mathrm{cm}^{2}\right)$ which far exceeds the damage threshold of $1.5 \mathrm{~J} / \mathrm{cm}^{2}$. That is, local absorption of heat would cause a small flaw to grow from shot to shot quickly leading to failure. If the surface were composed of a thin liquid metal film (grazing incidence liquid metal mirror or GILMM), surface imperfection would heal due to surface tension and due to fresh flowing liquid. If dust or other contaminant should land on the surface it will be slowly swept away $(\sim 100$ $\mathrm{s}$ to move $1 \mathrm{~m}$ down the mirror). Melting and even evaporation is not a problem. The surface must flow slowly enough so that no shear flow instabilities cause a surface ripple. Heat must be removed from the back by conduction, not convection at the slow flow rates required to avoid surface ripple. There was previous mention in the literature of using liquid metal surfaces for laser fusion mirrors by Hovingh et al. in $1973^{4}$ and by Baird and Anderson in $1975^{5}$. Liquid metals (mercury) have already found application in telescopes based on a thin ( $\sim 1 \mathrm{~mm}$ thick), 2.7-m diameter slowly rotating pool supported on an air bearing to form a parabolic mirror ${ }^{6}$.

The GILMM might last the life of the plant (>30 y) being limited by damage to the substrate. The second optical element which is out of the line of sight of the microexplosion can be of conventional optics design, e.g. dielectric coatings or refractive or diffractive $\mathrm{SiO}_{2}$. An alternative concept for final optics is use of $\mathrm{SiO}_{2}$ operated so hot $\left(400^{\circ} \mathrm{C}\right)$ that damage is annealed continually. ${ }^{7}$ It is not known how long such materials can continue to serve as quality optics. GILMM appear 
to be a complete solution to the final optics, being radiation hard to both neutrons and $x$ rays, having long service life of $>30$ years and acceptable cost while being able to deliver high quality laser light to the target. Some or all of the final focusing can be accomplished with the GILMM by curving the substrate surface and using adaptive optics. The ideas presented in this paper might find application in making low cost telescope mirrors. Another application of GILMM might be final optics in laser fusion propulsion of space $\mathrm{craft}^{8}$. In space a slowly rotating set of GILMMs can function as discussed in this paper.

\section{System layout}

The final optics in two designs using direct drive are shown in Fig. 1 and 2. The angle of the beam lines (where $0^{\circ}$ is horizontal and $90^{\circ}$ is vertical) is up $67^{\circ}$ in Fig. 2 (the mirrors are $5^{\circ}$ steeper so are sloped up to $72^{\circ}$ ). In the lower half of the chamber the mirrors are sloped $5^{\circ}$ less steep so the mirrors there are sloped up to only $62^{\circ}$. The distance to the final optics is $20 \mathrm{~m}$ in Fig. 1 and $30 \mathrm{~m}$ in Fig 2. For our examples we will use $30 \mathrm{~m}$ as well. The cross section of the beam in Figure 2 is $1 \mathrm{~m}$ by $0.43 \mathrm{~m}$. The "foot print" on the $84^{\circ}$ grazing incidence mirror is then $1 \mathrm{~m}$ by $4.1 \mathrm{~m}$ in the direction down the slope.

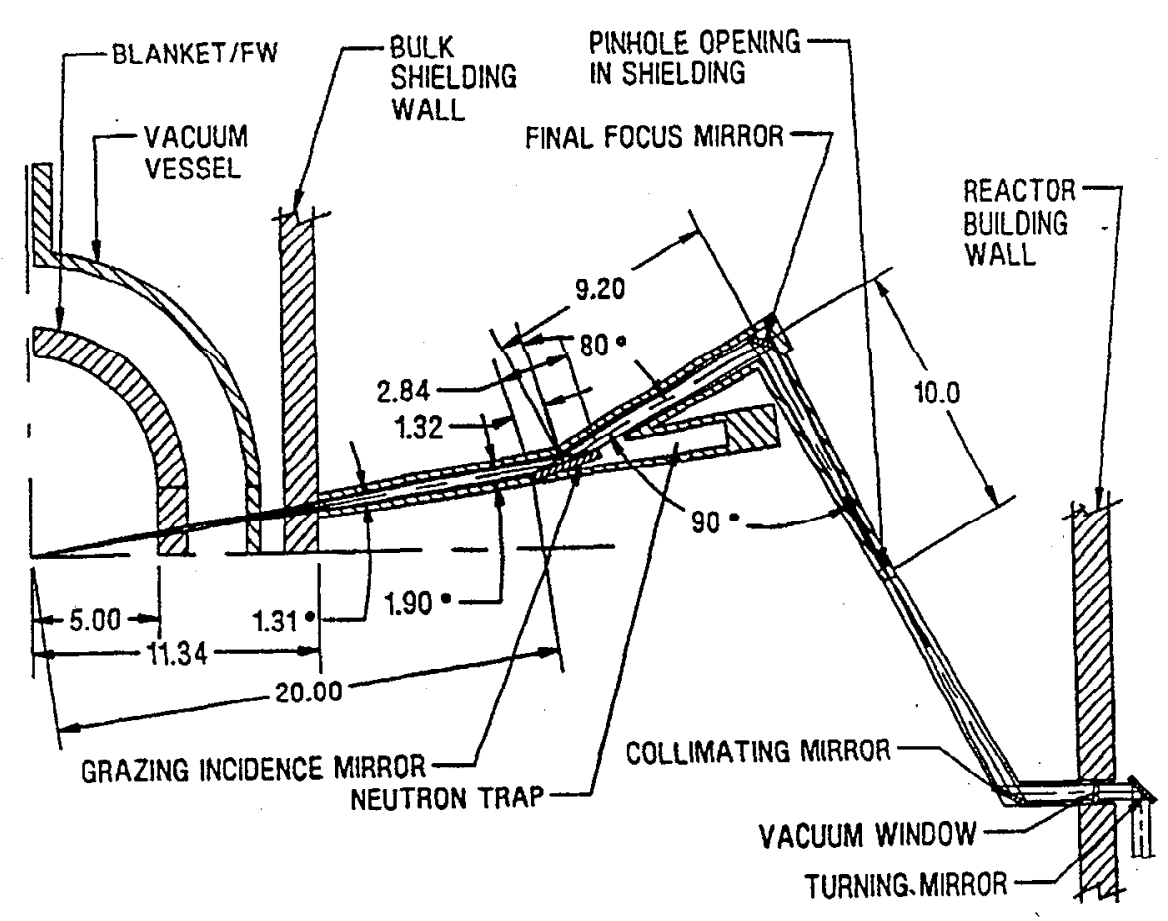

Fig. 1. Final optical elements in the Prometheus reactor design 


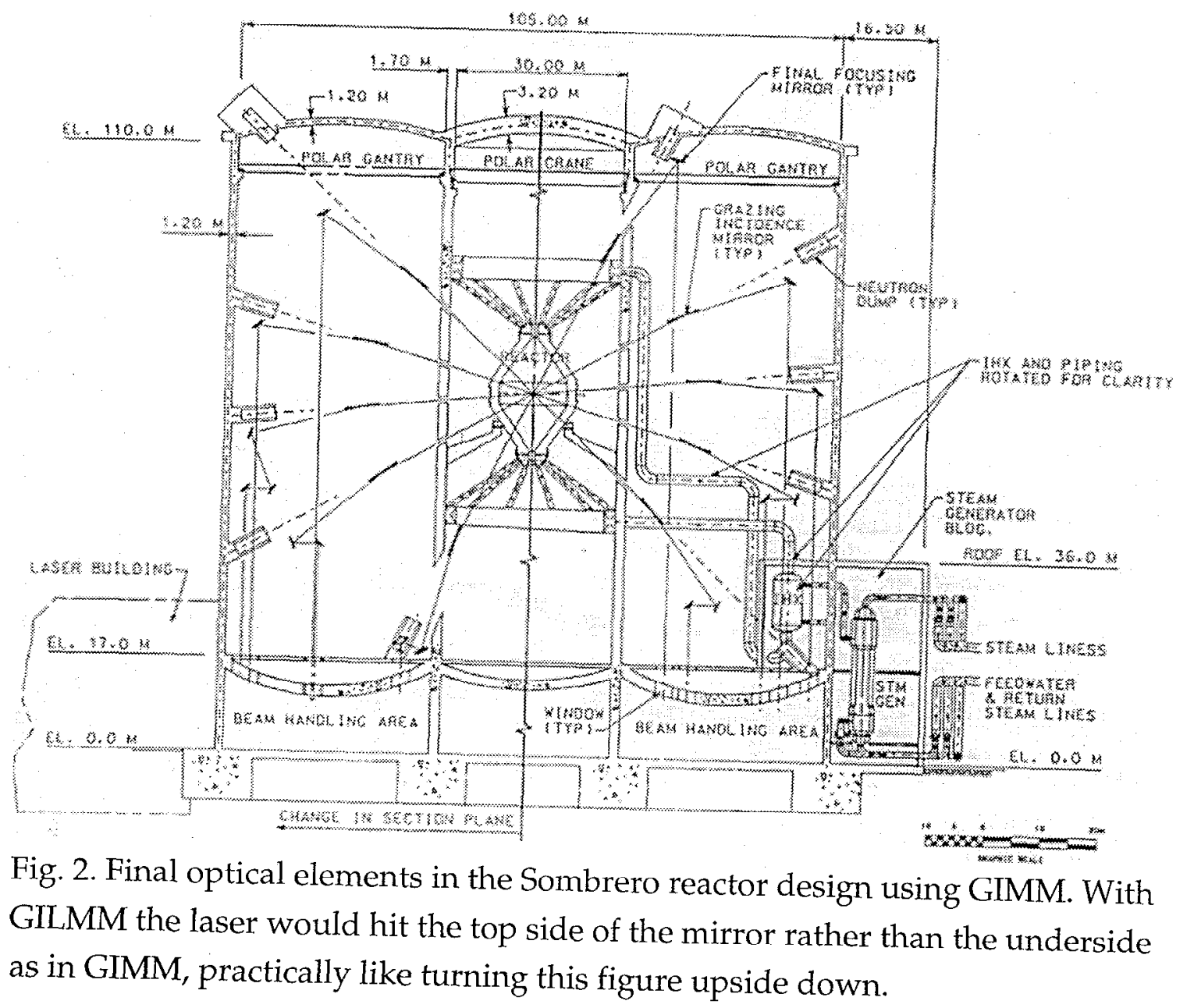




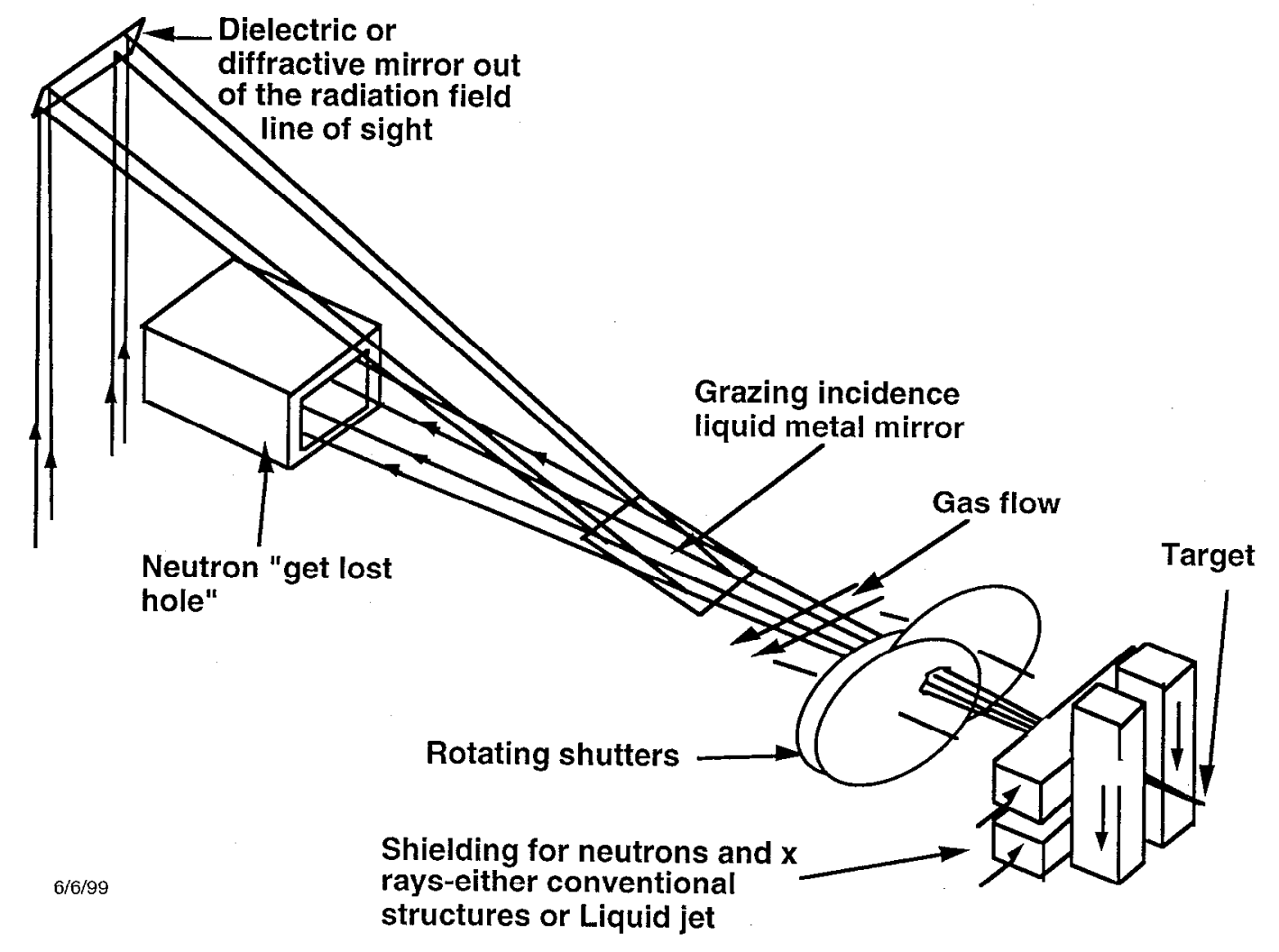

Figure 3. Typical optics layout showing key protection features.

Examples of optical layouts are given in Fig. 3 showing shutters and gas flow to keep debris from reaching the GILMM. Dielectric mirrors are shown based on present day practice which should be applicable out of the radiation environment but diffractive optics might be used as well.

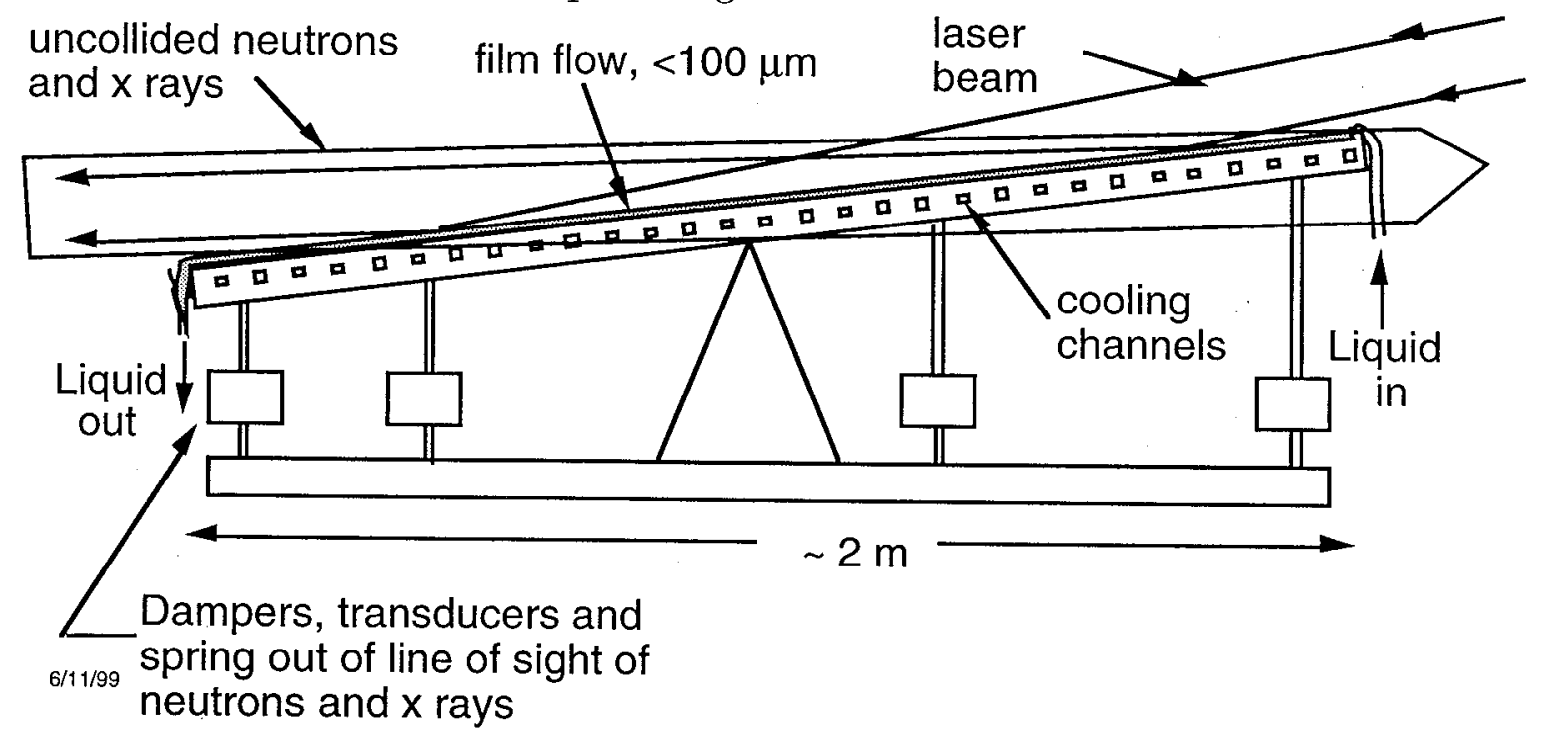

Fig. 4. Grazing incidence liquid metal mirror (GILMM) 
A schematic of GILMM is shown in Fig. 4. The surface shape is controlled by methods of adaptive optics where servos turn a screw connected to a spring in order to vary a force pushing or pulling at as many places as necessary on the back of the mirror. The adaptive optics with servos are intended to correct for changes in shape over minutes or hours or longer; however, with piezo-electric transducers, beam pointing from shot to shot can be accomplished if needed in times of $<0.1 \mathrm{~s}$. The liquid is fed in at the top of the inclined plane with care so that the feed rate is constant across the mirror and disturbances are minimal. Small variation in entrance conditions will smooth out as the liquid flows down the plane. The liquid must wet the surface at all times. If dry out occurs for some reason, vapor deposition methods could be used to recoat, however, this would require a plant shut down which should be avoided if at all possible and therefore is a serious concern that will need research. Heat deposited by the laser, $x$ rays and neutrons must be removed from the back by conduction, not convection at the slow flow rates required to avoid surface ripple. The servos and robotics for the GILMM can be out of line of sight of neutrons and $x$ rays. The first and only structures to "see" uncollided neutrons will be the GILMM at $30 \mathrm{~m}$ distance from the shot point. There is reasonable hope the mirrors can last the life of the plant. There will be need for a pump (EM pump with no moving parts) and filter system to circulate the liquid metal and keep it clean.

\section{Damage limit theory}

The light pulse on the surface causes a temperature rise until some effect sets a limit we will call the damage limit light flux in $J / \mathrm{cm}^{2} . R_{S}$ and $R_{p}$ are the reflectivities for the case where the electric field is parallel and perpendicular to the plane from Ref. 9 and 1.

$$
\begin{aligned}
& R_{S}=\frac{u^{2}+\mathrm{v}^{2}-2 u \cos \phi+\cos ^{2} \phi}{u^{2}+\mathrm{v}^{2}+2 u \cos \phi+\cos ^{2} \phi} \\
& R_{P}=R_{S} \cdot \frac{u^{2}+\mathrm{v}^{2}-2 u \sin \phi \tan \phi+\sin ^{2} \phi \tan ^{2} \phi}{u^{2}+\mathrm{v}^{2}+2 u \sin \phi \tan \phi+\sin ^{2} \phi \tan ^{2} \phi}
\end{aligned}
$$

where $\mathrm{u}$ and $\mathrm{v}$ are defined as: 
$2 u^{2}=\left(n^{2}-k^{2}-\sin ^{2} \phi\right)+\left[\left(n^{2}-k^{2}-\sin ^{2} \phi\right)^{2}+4 n^{2} k^{2}\right]^{1 / 2}$

$2 v^{2}=-\left(n^{2}-k^{2}-\sin ^{2} \phi\right)+\left[\left(n^{2}-k^{2}-\sin ^{2} \phi\right)^{2}+4 n^{2} k^{2}\right]^{1 / 2}$

Where $\mathrm{n}$ and $\mathrm{k}$ are the frequency (wavelength) dependent refractive index and extinction coefficient of the liquid metal. The angle of incidence relative to the normal is $\phi$ and the electric field is polarized in the direction of the plane or perpendicular to the plane. The temperature rise at the surface, $\Delta \mathrm{T}$ is given next.

$$
\begin{aligned}
& \Delta T=\frac{2(1-R) q_{\text {beam }}}{k_{T}}\left(\frac{\alpha_{T} t}{\pi}\right)^{1 / 2} \\
& \alpha_{T}=\frac{k_{T}}{\rho c}
\end{aligned}
$$

Where $R$ is the reflectivity, qbeam is the power density of the optical beam on the metal surface, $t$ is the time duration of the pulse, $\rho$ is the density of the metal, $\alpha_{T}$ is the thermal diffusivity, $\mathrm{k}_{\mathrm{T}}$ is the thermal conductivity and $\mathrm{c}$ is the heat capacity of the liquid metal. The skin depth or optical penetration depth is discussed in the section after the next one on effects of absorption and heating.

\section{Candidate liquids}

The choice of material for GILMM will be based on the damage limited heat flux and ease of handling. The mechanism that sets the damage limited heat flux is thought to be avoiding liquid ablation (spall) caused by the sudden heating (isochoric heating) and subsequent rapid expansion. The surface temperature rises monatonically until the end of the pulse. We arbitrarily set $200{ }^{\circ} \mathrm{C}$ as a measure of the damage limited heat flux until liquid ablation calculations are performed with hydro codes (ABLATOR ${ }^{10}$, for example). For comparison Bieri ${ }^{1}$ found a temperature rise limit of about $100^{\circ} \mathrm{C}$ set by surface distortion (strain beyond the elastic limit for $\mathrm{Al}$ at room temperature). The light intensity at 0.35 $\mu \mathrm{m}$ for $200^{\circ} \mathrm{C}$ temperature rise is given in Table 1 for a number of candidate liquids. Liquid lithium and mercury are possible but marginal especially when it comes to the short pulsed ignitor beams. Sodium or even aluminum may be the best choice as will be discussed further on. For the compressor beams the damage limit of GILMM is so high that the limit will be set by the optics that 
follow out of line of sight of neutrons. This is likely even for the ignitor beams. The peak pressure, $P$, given in Table 1 is the Gruneisen pressure without any hydro motion, that is $\mathrm{p}=\Gamma \mathrm{E} / \mathrm{V}$ where $\Gamma$ is the Gruneisen parameter (usually near unity). The energy is deposited at the surface in a volume $V$. As the surface heats up, expansion occurs at the speed of sound so the pressure falls short of the values given in Table 1 . These need to be calculated with a hydro code.

The reflectivity varies with angle as shown in Fig. 5 and with wavelength shown in Fig. 6 and 7. Clearly, we can see the importance of orienting the mirror so that the electric field is in the plane of the film. Commonly in inertial fusion the intense portion of the laser pulse is 8 to $10 \mathrm{~ns}$ long. However, it might be as long as $20 \mathrm{~ns}$ if a slow compression is used to make a dense cold core for fast ignition. Therefore, for our examples we assume a typical pulse is $20 \mathrm{~ns}$ long or in the case of fast ignitor $10 \mathrm{ps}^{11}$. The pulse length at the mirror might be much longer than this $10 \mathrm{ps}$. The results can easily be scaled to different pulse lengths. The allowed intensity scales as square root of the pulse length. The highest intensity allowed is for liquid $\mathrm{Al}$, however, its high melting point of $660^{\circ} \mathrm{C}$ suggest use of liquid $\mathrm{Na}$ or Li may be more practical with their melting points of 98 and $179{ }^{\circ} \mathrm{C} . \mathrm{Hg}$ and $\mathrm{Pb}$ have considerable lower damage threshold. Mercury has a low vapor pressure at low temperature and will not react with Flibe. $\mathrm{Li}$ and $\mathrm{Na}$ have the additional advantage, their oxides and fluorides are dense enough to sink rather than form a (slag) that might interfere with reflection and make clean up harder. Wetting is a serious issue. Lithium should be able to wet steel once the oxide has been removed, which can be done a number of ways including submersing in $\mathrm{Li}$ at $600{ }^{\circ} \mathrm{C}$ for a few hours ${ }^{12}$ to remove the oxides. Similar properties should apply to other alkali metals such as sodium. 


\section{Table 1}

Damage limit for $20 \mathrm{~ns}$ pulses for a $200{ }^{\circ} \mathrm{C}$ surface temperature rise

\begin{tabular}{|c|c|c|c|c|c|l|l|c|}
\hline & $\begin{array}{c}\text { Tmell } \\
{ }^{\circ} \mathrm{C}\end{array}$ & \multicolumn{2}{|c|}{ Pressure, Torr, } & $\begin{array}{c}\text { Laser fluence } \\
\text { on mirror } \\
\left(85^{\circ}\right), \mathrm{J} / \mathrm{cm}^{2} \\
(\text { absorbed })\end{array}$ & $\begin{array}{l}\text { Peak } \\
\text { pressure, } \\
\mathrm{GPa}\end{array}$ & $\begin{array}{l}\text { Laser } \\
\text { fluence } \\
\text { transverse } \\
\text { to beam, } \\
\mathrm{J} / \mathrm{cm}^{2}\end{array}$ & $\begin{array}{c}\text { Mirror area } \\
\text { for 60 kJ per } \\
\text { beam, }{ }^{2}\end{array}$ \\
\hline $\mathrm{Al}$ & 660 & $100^{\circ} \mathrm{C},+300^{\circ} \mathrm{C}$ & $1 \cdot 10^{-4}$ & 9.2 & $(0.064)$ & 2.1 & 106 & 0.65 \\
\hline $\mathrm{Na}$ & 98 & $1.2 \cdot 10^{-4}$ & $3 \cdot 10^{-1}$ & 5.0 & $(0.025)$ & 0.16 & 57 & 1.2 \\
\hline $\mathrm{Ga}$ & 30 & $4 \cdot 10^{-26}$ & $4 \cdot 10^{-15}$ & 2.4 & $(0.022)$ & 0.4 & 28 & 2.5 \\
\hline $\mathrm{Li}$ & 179 & $2 \cdot 10^{-6}$ & $3 \cdot 10^{-3}$ & 0.67 & $(0.025)$ & 0.8 & 7.7 & 9.0 \\
\hline $\mathrm{Hg}$ & -39 & $2 \cdot 10^{-2}$ & $3 \cdot 10^{0}$ & 0.53 & $(0.010)$ & 0.3 & 6.0 & 11 \\
\hline $\mathrm{Pb}$ & 328 & $7 \cdot 10^{-7}$ & $1 \cdot 10^{-3}$ & 0.33 & $(0.013)$ & 0.7 & 3.8 & 18 \\
\hline $\mathrm{Al}(\mathrm{solid}) \mathrm{Sombrero}$ & & 1.5 & & & 14 & 4.1 \\
\hline
\end{tabular}

The Sombrero design as discussed in the introduction had a mirror area of $4.1 \mathrm{~m}^{2}$ with a laser intensity on the mirror of $1.5 \mathrm{~J} / \mathrm{cm}^{2}$. From the last column of Table 1 we can compare the area of GILMM with the various liquid metals to the area of GIMM of Sombrero of $4.1 \mathrm{~m}^{2}$. Aluminum stands out and sodium is pretty good. Lithium is larger by a factor of two. The damage limit scales as (pulse length) ${ }^{0.5}$, so that a $10 \mathrm{ps}$ pulse could only handle a factor of 45 times less energy for the same surface temperature rise. If the ignitor pulse at the mirror had not fully compressed but rather were 200 ps long there, then the damage limit would be reduced by a factor of 10 from those in Table 1 . For the compressor beams the damage limit of GILMM is so high that the limit will be set by the optics that follow out of line of sight of neutrons. This is likely even for the ignitor beams. 


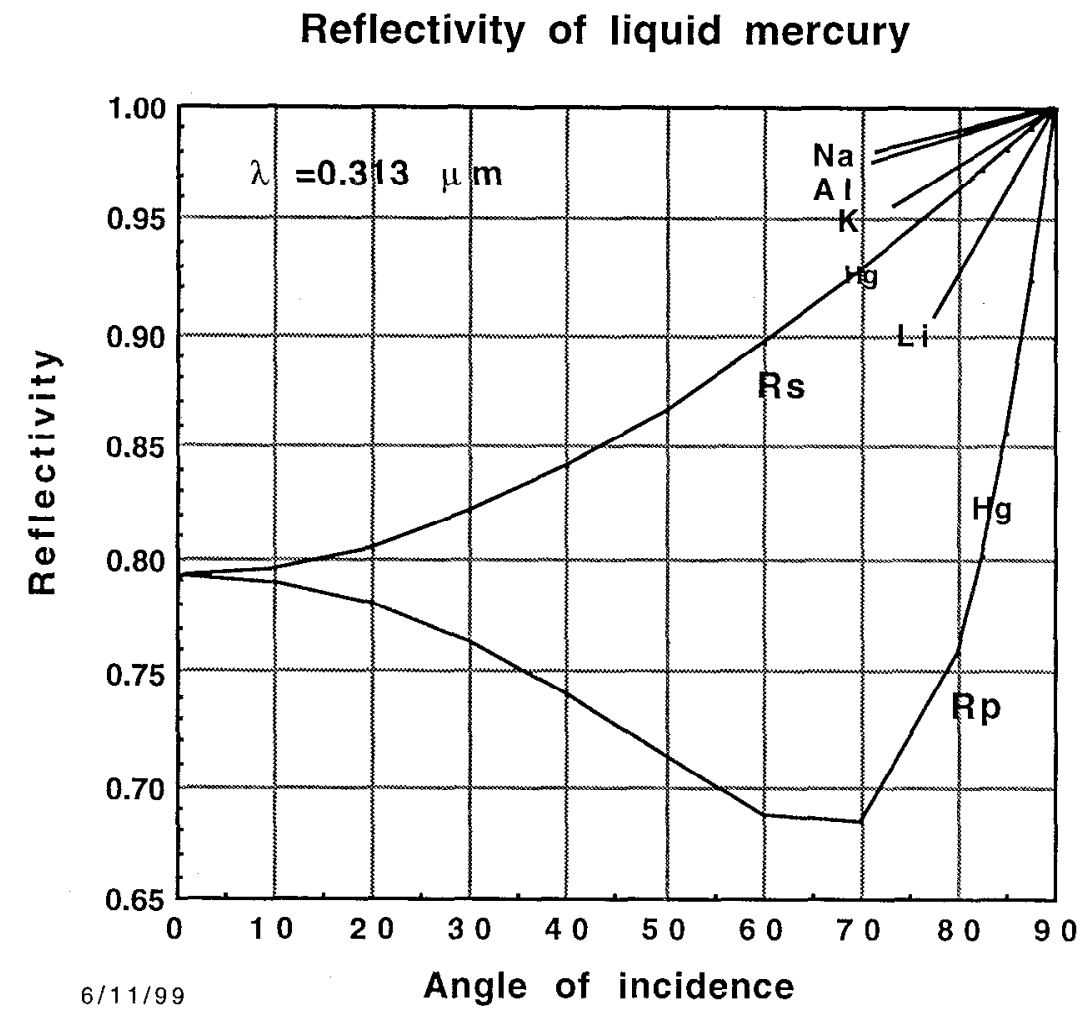

Figure 5. Reflectivity versus angle of incidence for mercury. The curve labeled $R_{S}$ has the electric field parallel to the surface and $R_{p}$ has a component of the electric field perpendicular to the surface. For comparison the reflectivities for other liquid metals are shown.

There are a number of effects that contribute to absorptance (1-R) discussed by Bieri $^{1}$ that have been neglected and need to be added to the analysis here. 


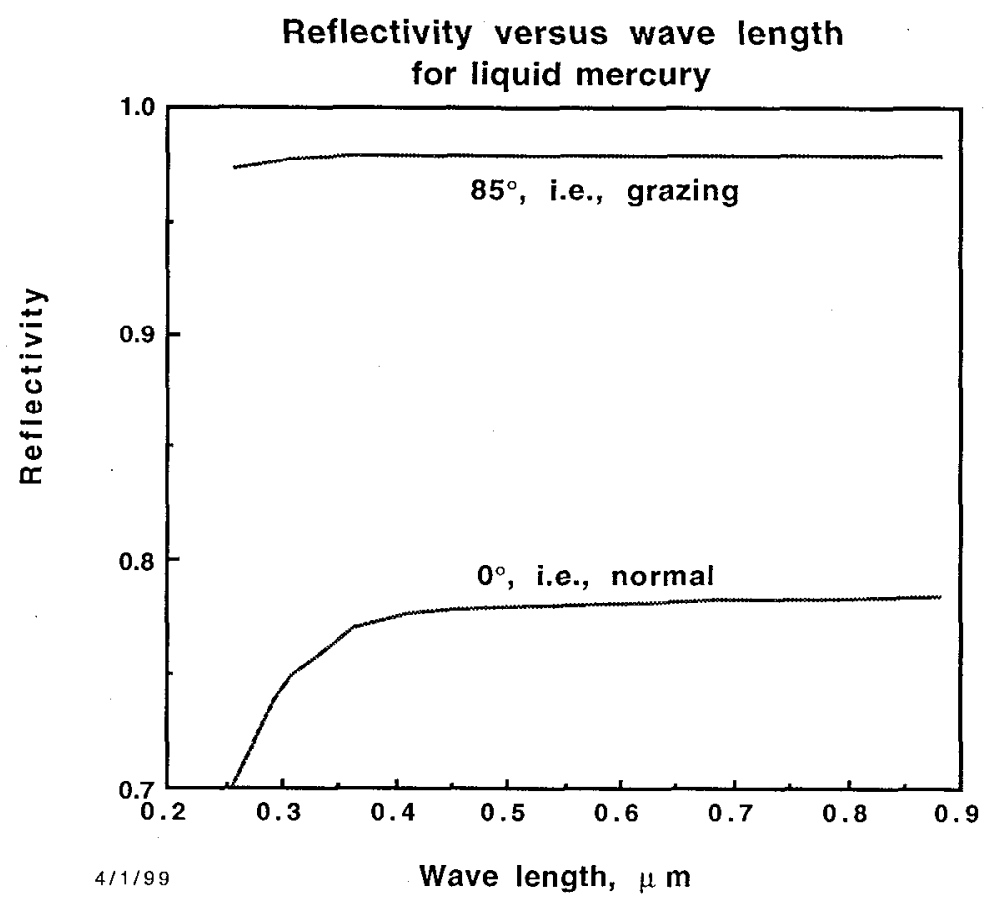

Figure 6. Reflectivity versus wave length for mercury

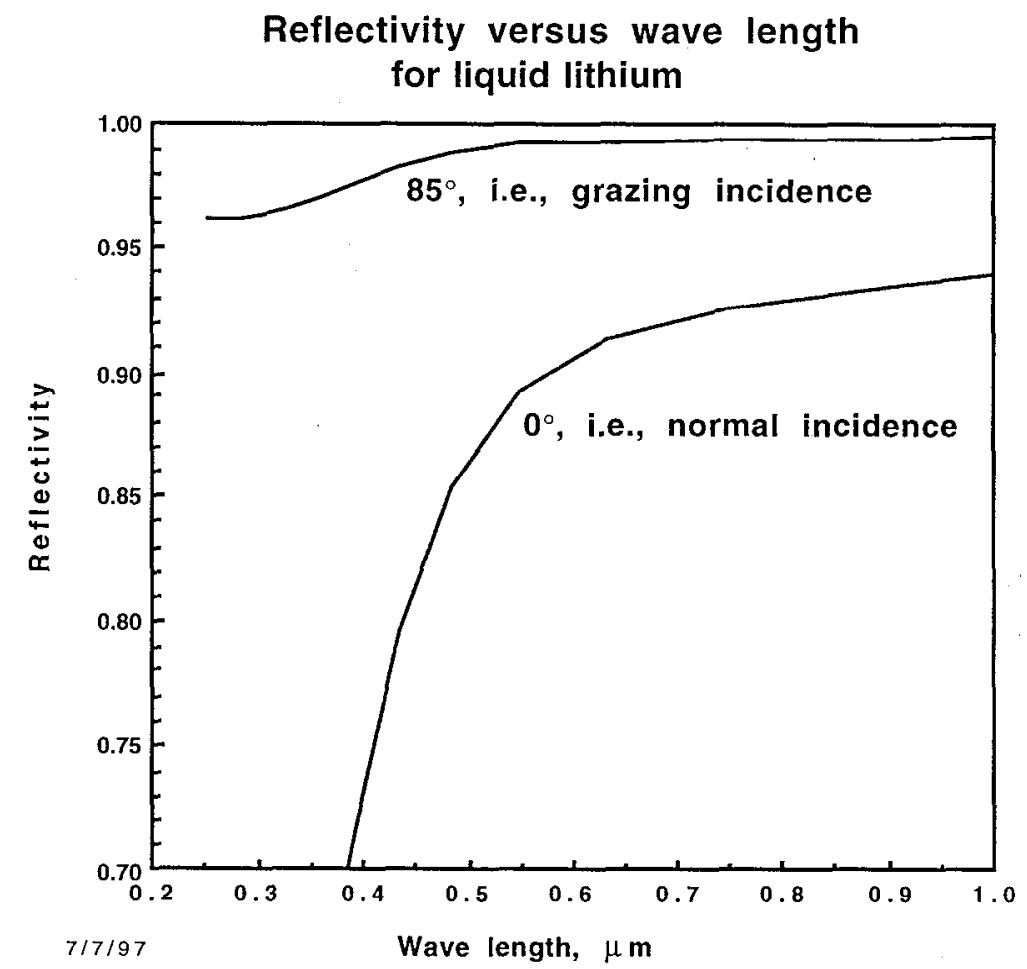

Figure 7. Reflectivity versus wave length for liquid lithium 
The performance of GILMM might be strongly effected by wavelength of possible lasers. For $\mathrm{Li}$ the damage limit for $1 / 4$ and $1 / 3 \mu \mathrm{m}$ light is about the same but is about 2.8 times higher for $1 / 2 \mu \mathrm{m}$ light and 7.3 times higher for $1 \mu \mathrm{m}$ light compared to $1 / 3 \mu \mathrm{m}$ light.

\section{Optical penetration and sound travel time effects}

The question comes up of how deep is the optical penetration compared to the thermal diffusion distance for two reasons. Liquid surfaces are not characteristic of the bulk for the first few atomic distances into the interior and the surface may have some contaminants on it. Does either of these effects matter? Also the peak pressures shown in Table 1 are diminished by a relief wave traveling at the speed of sound during the heating pulse so as to reduce the peak pressures and hence the peak tension as well. These effects are illustrated in Table 2 . The optical penetration depth is not many atom layers into the interior for most of the candidate liquids at $85^{\circ}$ incidence. This may be a reason to change to $80^{\circ}$ in future studies. For all cases the distance heat diffuses during the pulse is long compared to the optical penetration distance. For pulse lengths of $20 \mathrm{~ns}$, sound waves can diminish the pressure build up due to the heating during the pulse to a great extend but only somewhat for the $10 \mathrm{ps}$ pulses characteristic of fast ignitor beams.

The thermal diffusion length, $\ell_{\text {diff }}$ is $\ell_{\text {diff }}=\left(t \frac{k_{T}}{\rho c}\right)^{1 / 2}$

where the symbols are defined in Eq. 5 and 6. 
Table 2

Optical penetration and sound travel times

\begin{tabular}{|c|c|c|c|c|c|}
\hline & \multirow{2}{*}{$\begin{array}{l}\text { Optical } \\
\text { penetration, } 85^{\circ} \\
\text { incidence, } \AA \text {, }\end{array}$} & \multicolumn{2}{|c|}{ Thermal diff. distance, $\ell_{\text {diff }}, \mu \mathrm{m}$} & \multicolumn{2}{|c|}{$\begin{array}{l}\text { Distance sound } \\
\text { travels, } \mu \mathrm{m} \text { in }\end{array}$} \\
\hline & & $20 \mathrm{~ns}$ pulse & $10 \mathrm{ps}$ pulse & $20 \mathrm{~ns}$ & $10 \mathrm{ps}$ \\
\hline $\mathrm{Al}$ & 6.9 & 1.2 & 0.028 & 9.2 & 0.064 \\
\hline $\mathrm{Na}$ & 24 & 1.1 & 0.025 & 50 & 0.025 \\
\hline $\mathrm{Ga}$ & 5.5 & 0.54 & 0.012 & 40 & 0.02 \\
\hline $\mathrm{Li}$ & 20 & 0.67 & 0.015 & 40 & 0.02 \\
\hline $\mathrm{Hg}$ & 9.7 & 0.30 & 0.0066 & 29 & 0.015 \\
\hline $\mathrm{Pb}$ & 7.7 & 0.46 & 0.010 & 36 & 0.018 \\
\hline
\end{tabular}

$(1 \mu \mathrm{m}=10,000 \AA)$

\section{Theoretical basis for smooth film flow}

The film must be sufficiently thin so that viscous forces overcome shear effects that lead to wave buildup. According to theoretical analysis, if the Reynolds number is below the critical value, disturbances will damp rather than grow. Short wave length disturbances damp quicker than long wave disturbances and when surface tension (which is unimportant at long wavelengths $>100 \mathrm{~mm}$ ) is included, short wave disturbances damp even more quickly. All this suggests that impulses delivered at 5 to $10 \mathrm{~Hz}$ or higher may not be a problem as will be discussed later. That is, a disturbance might damp out by the next pulse. Heat removal, discussed later, by subsurface cooling channels will keep temperature variation over the film surface small.

The film flow Reynolds number from Ref. 13 is given in Eq. 7, where $\rho$ is density, $h_{0}$ is the film thickness, $\eta$ is viscosity and $\theta$ is the angle of the film flow plane.

$\mathrm{Re}=\frac{\rho^{2} g h_{0}^{3} \sin \theta}{2 \eta^{2}}$

Critical Reynolds number for stability of long wave length disturbances: 
$\operatorname{Re}_{\text {crit }}=\frac{5}{4} \cot \theta$

The surface flow speed $\mathrm{U}_{\mathrm{o}}$ is

$U_{0}=\frac{\rho g h_{0}^{2} \sin \theta}{2 \eta}$

where the average flow speed is $\frac{2}{3} U_{0}$

The Weber number is useful to show when surface tension effects might be important.

$W e=\frac{\sigma}{\rho g h_{0}^{2} \sin \theta}$

For lithium, whose viscosity, $\eta$, is $0.41 \mathrm{mPa} \cdot \mathrm{s}$ and surface tension, $\sigma$, is $0.35 \mathrm{~N} / \mathrm{m}$, we get a Weber number, We, of 4000 for $\theta=10^{\circ}$ and $100 \mu \mathrm{m}$ film thickness. Surface tension effects are extremely strong over dimensions comparable to the film thickness of interest. Disturbances with dimensions up to a few centimeters will be reduced strongly by surface tension but beyond a few centimeters surface tension is ineffective as will be discussed below and illustrated in Fig. 8 and 9.

The film thickness required for stable flow (Reynolds number is less than the critical Reynolds number from Eq. 8) is plotted in Fig. 8 and 9 for liquid Li and $\mathrm{Na}^{13}$ with the geometry and variables defined in Fig. 10. We can see that if the film is $<100 \mu \mathrm{m}$, then the surface should be smooth for a $10^{\circ}$ slope for $\mathrm{Na}$. What limits the minimum thickness is not known but maintaining wetting may be a limitation to thickness. 


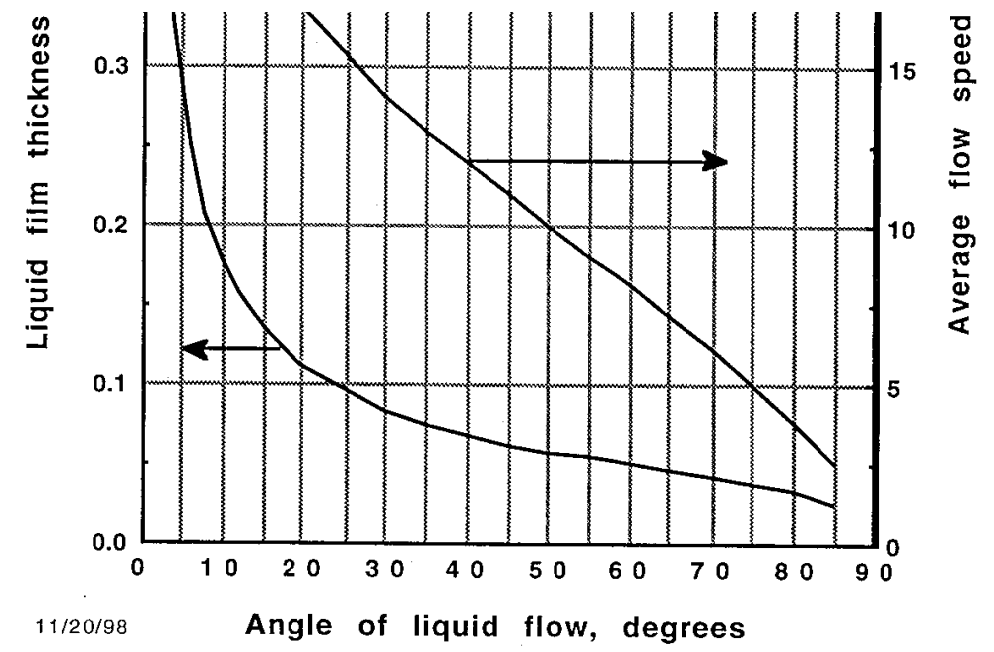

Fig. 8. Liquid film thickness and speed for laminar flow of lithium.

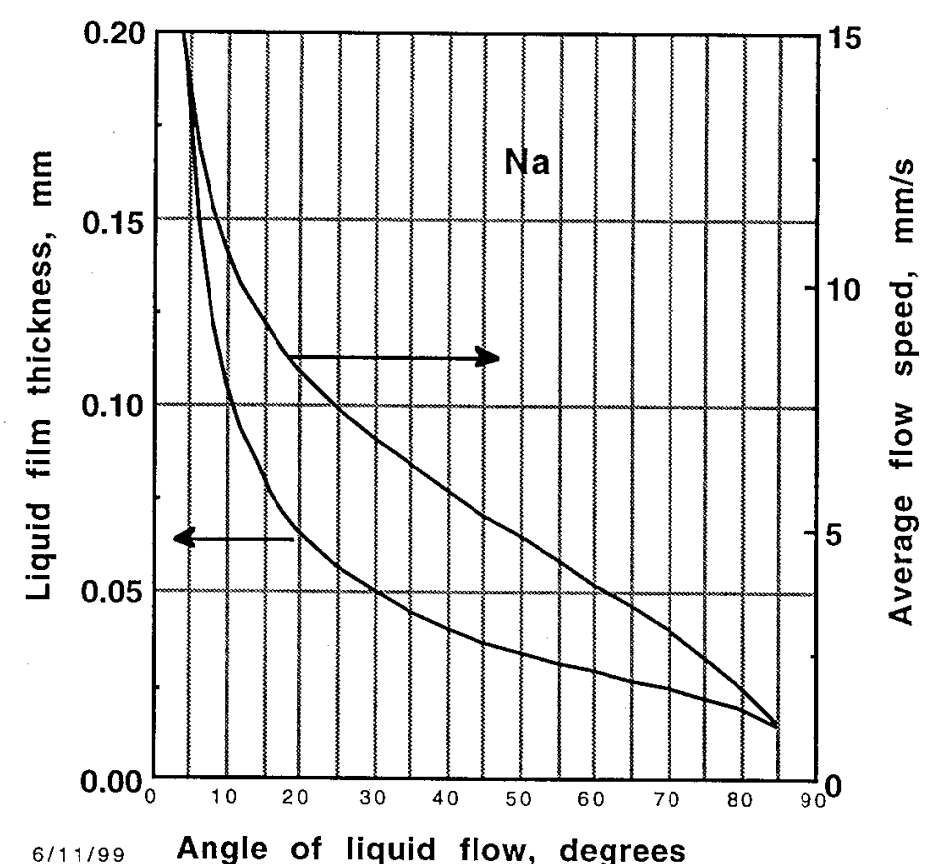

Fig. 9. Liquid film thickness and speed for laminar flow of sodium. 


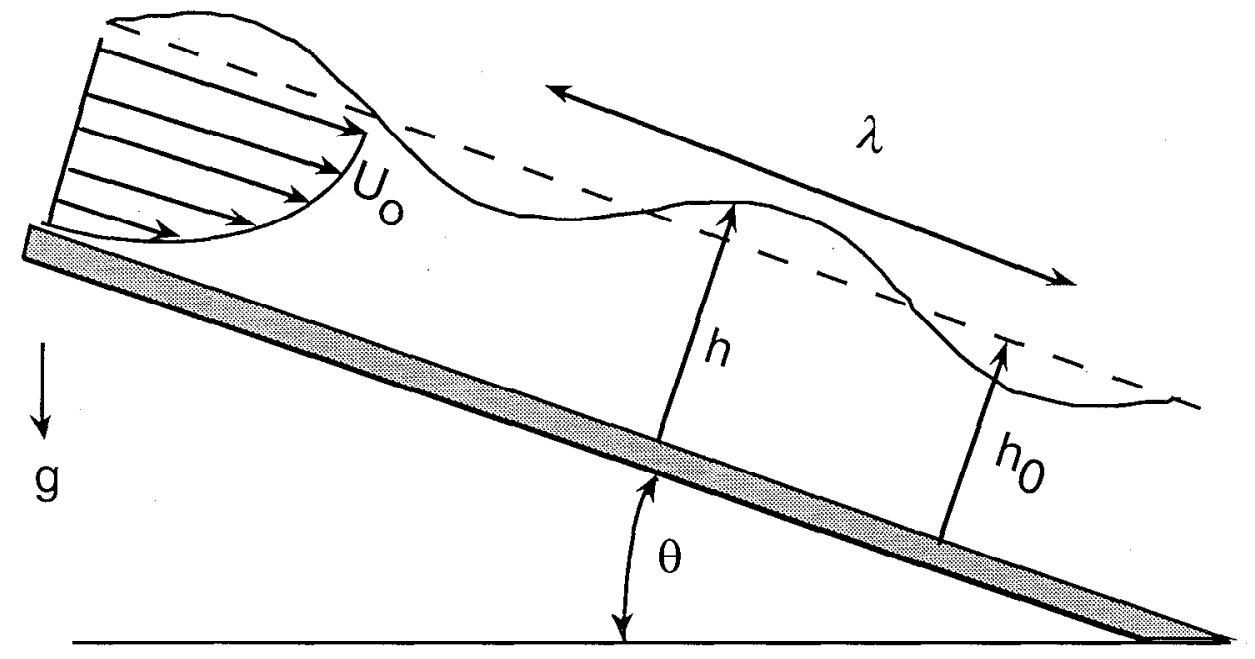

Fig. 10. The variables describing film flow down an inclined plane are shown above.

In the Sombrero study with direct drive, employing 60 beams, the steepest beam enters at $67^{\circ}$ (where $90^{\circ}$ would be directly overhead). With $5^{\circ}$ grazing, the mirror would be inclined to $72^{\circ}$. From Fig. 8 and 9 we see the thickness of film must be $<40 \mu \mathrm{m}$ for $\mathrm{Li}$ and $25 \mu \mathrm{m}$ for $\mathrm{Na}$ to avoid waves. Experiments will be needed to see if stable thin flowing films can be made especially for steep slopes.

\section{Stability of the flowing film}

When the film thickness is less than that shown in Fig. 8 and 9, the flow is laminar and stable according to the theory to long wavelength disturbances. We can imagine even with perfectly smooth steady flow, disturbances can be initiated by events such as laser heating of the surface at 5 to $10 \mathrm{~Hz}$ rate including uneven heating, acoustic motion due to gas (target debris) striking the surface, heating by neutrons and so forth. The metal backing is assumed to be fastened with damped actuators at multiple places behind the flowing surface. In the discussion to follow we estimate the rate of damping of disturbances of the liquid surface. We assume any disturbance can be decomposed into sinusoidal disturbances as shown in Fig. 10. From the analysis of Howard ${ }^{13}$ we find the growth rate of a disturbance of wavelength $\lambda$ is given by $\gamma$ : 
$\gamma=\frac{2 \alpha^{2}}{3 \sin \theta}\left[\left(\frac{6}{5} R \sin \theta-\cos \theta\right)-\frac{\Gamma}{g h^{2}} \alpha^{2}\right]$

$\alpha=\frac{2 \pi h}{\lambda}$

where $\Gamma$ is the surface tension. For the sake of the discussion to follow, we assume there is a disturbance produced by external factors such as the acoustical response of the laser heating or the gas shock that hits the surface of the mirror. The disturbance can be Fourrier analyzed into sinusoidal components with a given wavelength. This is the meaning of disturbance we are using. The growth exponent, $G$, is defined as growth of the disturbance, $e^{G}$, where for a $1 \mathrm{~m}$ distance down the flow path $\mathrm{G}$ is given as:

$G=\frac{U_{0}}{h} \gamma\left(\frac{100}{2 U_{0}}\right)=50 \frac{\gamma}{h}$

where Uo is the surface speed and $\gamma$ is the growth rate. Two cases are treated, one for 5 degree slope and the other for 70 degree slope to illustrate the range of parameters involved including the direct drive option. Fig. 11 and 12 shows the 5 degree case in linear and a log plot for Li. Fig. 13 and 14 show the 70 degree case for Li. Sodium is shown in Fig. 15 and 16. When the film is thicker than that shown in Fig. 8 and 9 disturbances grow. Disturbances of wavelength below about $10 \mathrm{~cm}$ for 5 degrees and below $5 \mathrm{~cm}$ for 70 degree slopes are strongly damped due to the effects of surface tension. The damping rate becomes small for wavelengths longer than $10 \mathrm{~cm}$ for a 5 degree slope and longer than $5 \mathrm{~cm}$ for a 70 degree slope. Isochoric heating will set up sound waves that will travel from the mirror front to the back in times of $5 \mu$ s and from one end to the other in about $1 \mathrm{~ms}$. Since there is no net momentum in isochoric heating expansion, these sound waves should simply damp out after some number of transits. For a 5 degree slope from Fig. 8 we see a film $<0.3 \mathrm{~mm}$ will be stable and flow at a surface speed of $35 \mathrm{~mm} / \mathrm{s}$ for Li. However the waves travel at twice the surface speed giving $70 \mathrm{~mm} / \mathrm{s}$. In an interpulse time of $0.17 \mathrm{~s}$ for $6 \mathrm{~Hz}$ the distance a wave travels is $<12 \mathrm{~mm}$. To have one e-fold damping would correspond to a $\mathrm{C}_{\mathrm{s}}$ value at $1 \mathrm{~m}$ of $-83(1 / 0.012=83)$, which is obtained only for wavelengths of disturbances of $20 \mathrm{~mm}$ or less as can be seen in Fig. 8. Stated another way a 20 $\mathrm{mm}$ wavelength disturbance will damp (1/e) in $0.17 \mathrm{~s}$. A $10 \mathrm{~cm}$ wavelength disturbance will damp (1/e) in $1 \mathrm{~m}$ or $14 \mathrm{~s}(1 \mathrm{~m} / 70 \mathrm{~mm} / \mathrm{s})$. A $20 \mathrm{~cm}$ disturbance $(\mathrm{G}=-0.2$ at $1 \mathrm{~m})$ would damp $(1 / \mathrm{e})$ in a distance of flow of $0.5 \mathrm{~m}$ or $71 \mathrm{~s}$. If there 
is a driving force for surface displacement disturbances over distances greater than $10 \mathrm{~cm}$, there may be a problem because these disturbances may damp to slowly. Thinner films than $0.3 \mathrm{~mm}$ will damp disturbances more quickly. For the $70^{\circ}$ slope (Fig. 13 and 14), the damping rates are much smaller. More analysis and experimentation will be needed to prove surfaces can be kept sufficiently smooth for the application to IFE. Other than acoustical forces and vibrations from the mounting system, both of which can be virtually eliminated by design, we are hard pressed to find a mechanism to produce surface disturbances. Next we discuss the required smoothness.

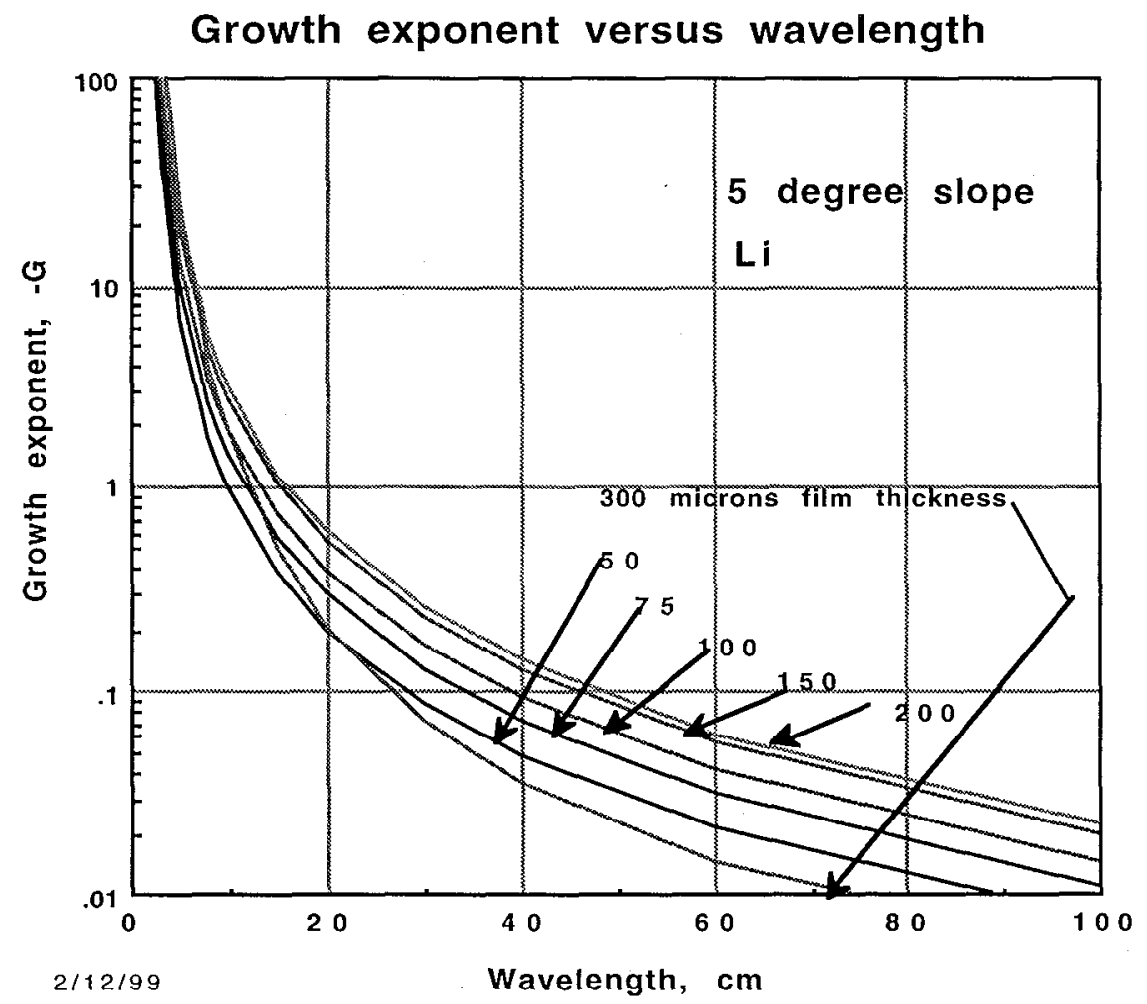

Fig. 11. Growth exponent (growth $\propto \mathrm{e}^{\mathrm{G}}$ ) versus wavelength for 5 degree slope film flow with liquid lithium plotted on a log graph for $1 \mathrm{~m}$ flow path (Howard Ref. 13). Note there is a thickness of the film that is the most stable or has the largest damping. 


\section{Growth exponent versus wavelength}

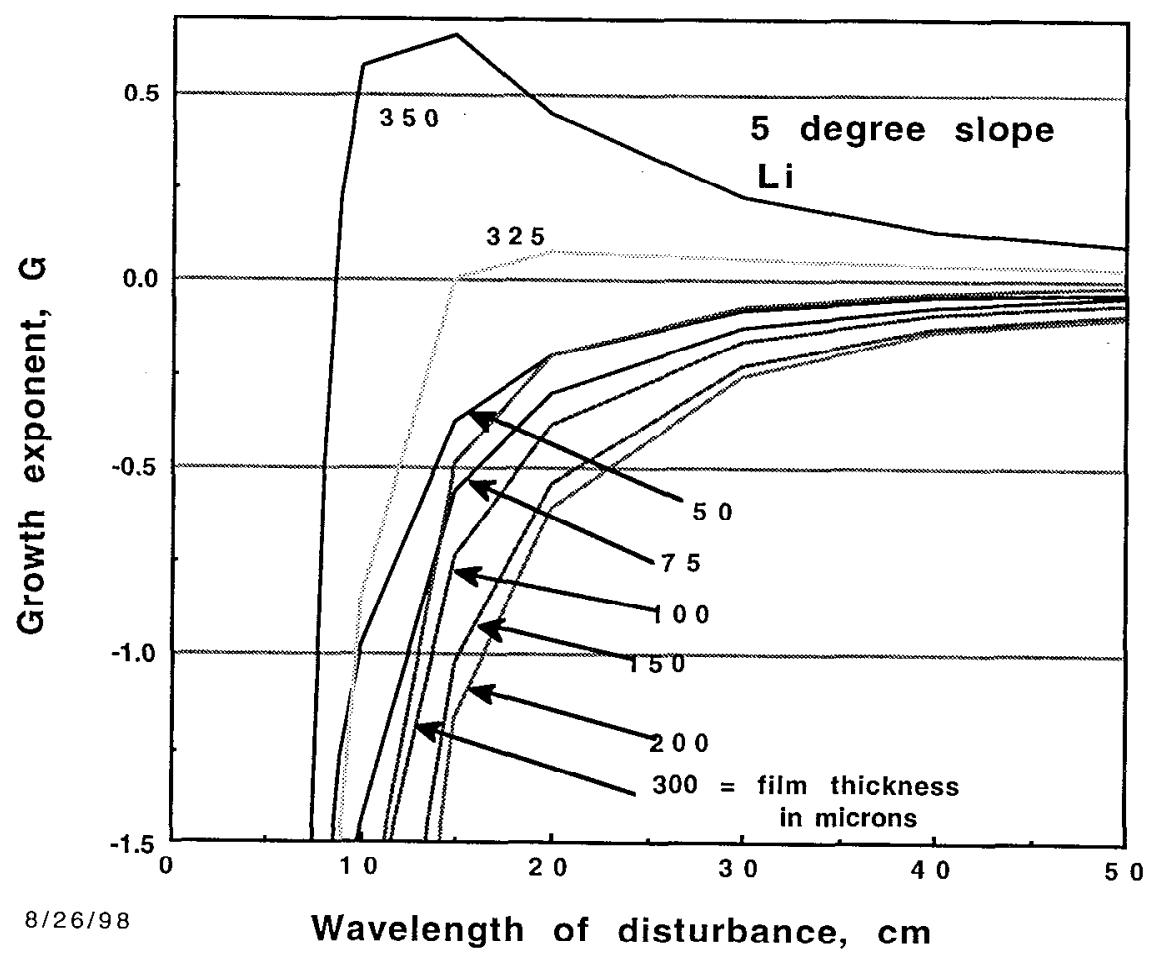

Fig. 12. Growth exponent (growth $\propto e^{G}$ ) versus wavelength for 5 degree slope film flow with liquid lithium plotted on a linear graph for $1 \mathrm{~m}$ flow path (Howard Ref. 13). Note there is a thickness of the film that is the most stable or has the largest damping. 

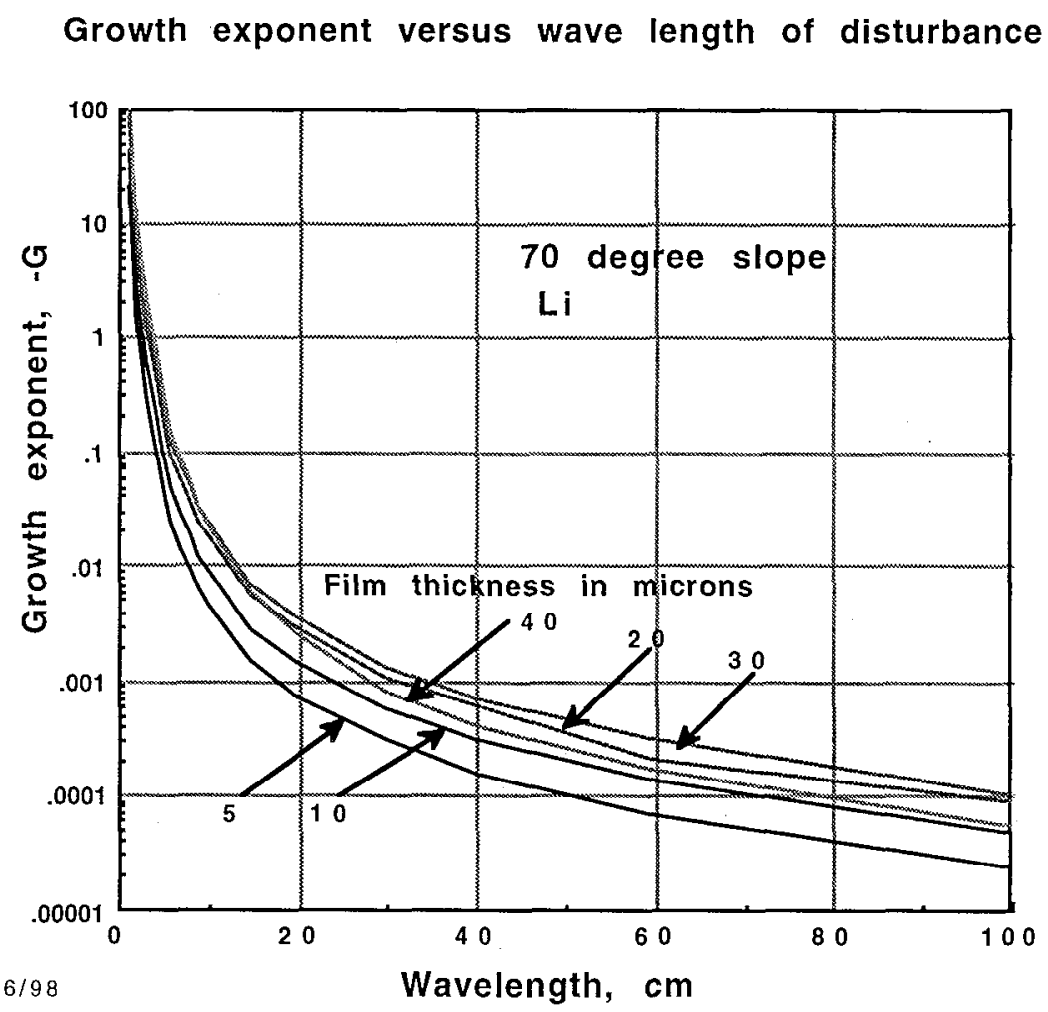

Fig. 13. Growth exponent versus wavelength for 70 degree slope film flow with liquid lithium plotted on a log graph for $1 \mathrm{~m}$ flow path. 


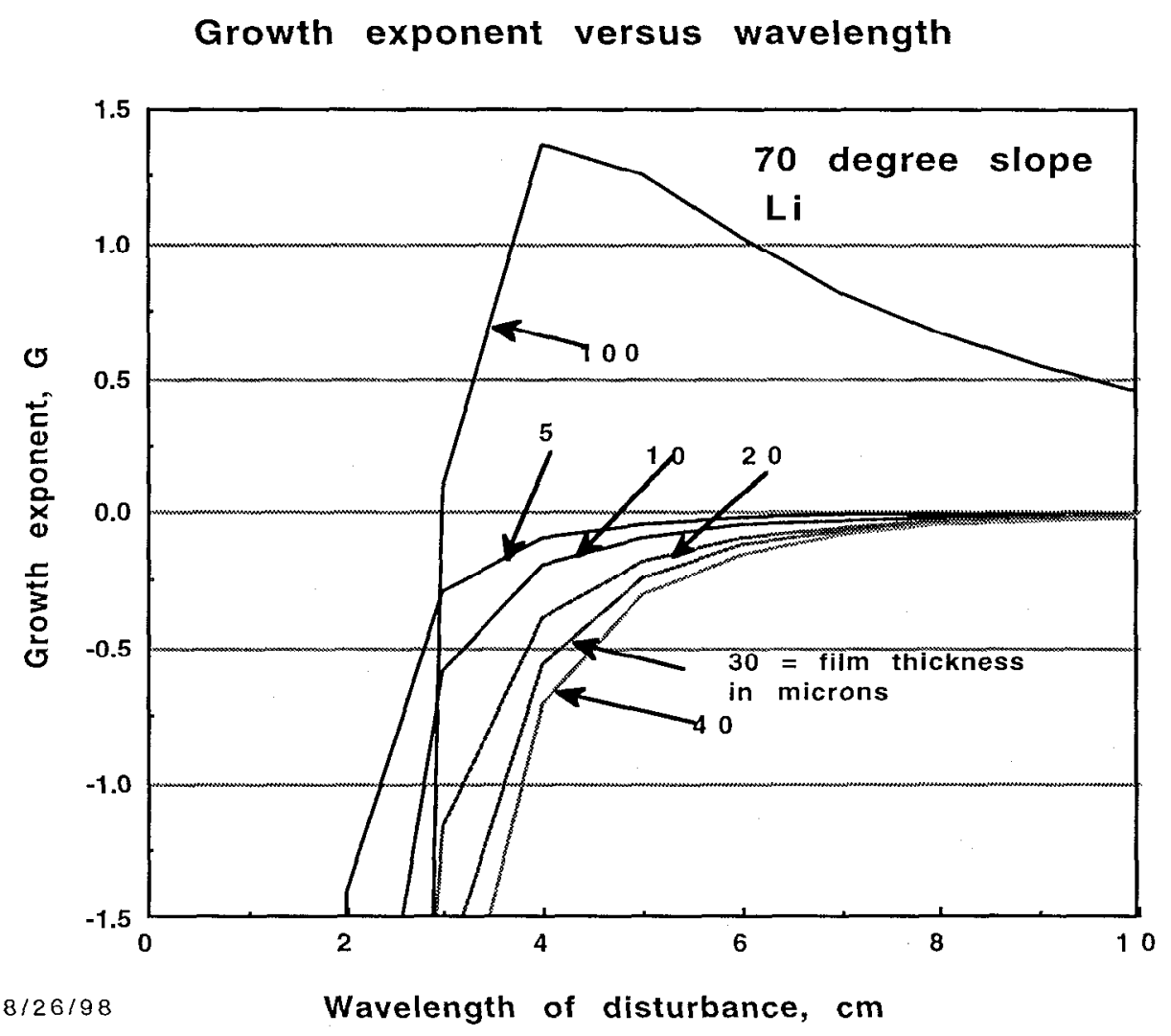

Fig. 14. Growth exponent versus wavelength for 70 degree slope film flow with liquid lithium plotted on a linear graph for $1 \mathrm{~m}$ flow path. 


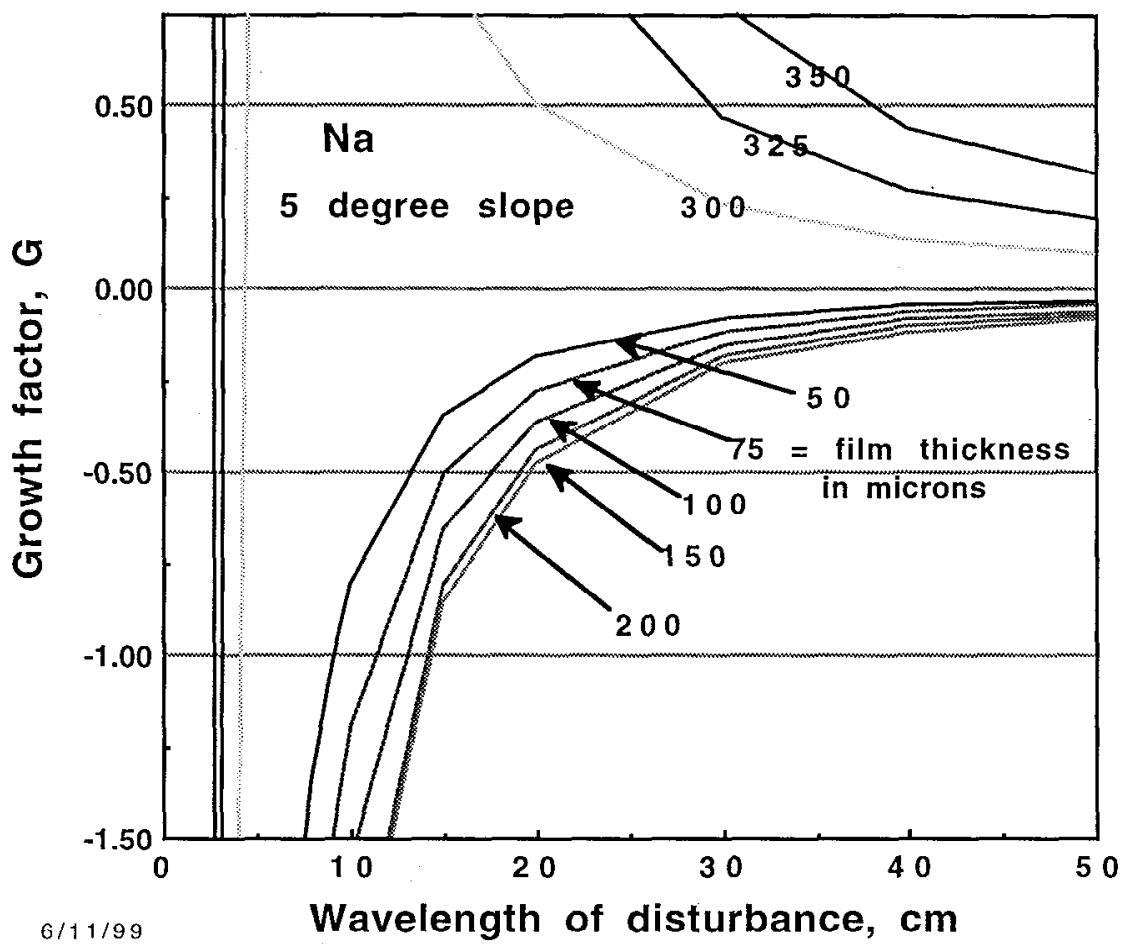

Fig. 15. Growth exponent versus wavelength for 5 degree slope film flow with liquid sodium plotted for $1 \mathrm{~m}$ flow path.

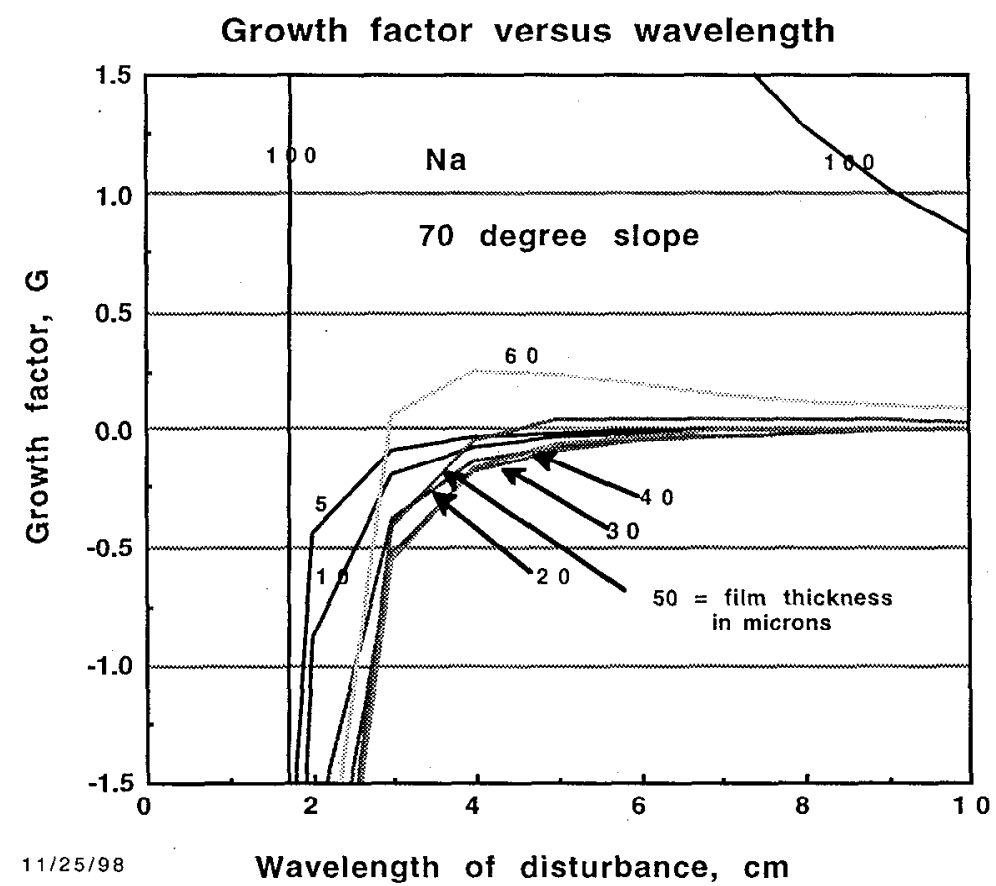

Fig. 16. Growth exponent versus wavelength for 70 degree slope film flow with liquid sodium plotted for $1 \mathrm{~m}$ flow path. 


\section{Required smoothness of the liquid film and metal substrate}

A simple analysis is done to show how smooth the liquid surface must be.

Suppose there is a sinusoidal surface ripple of $\pm \Delta h / h$, over a wavelength, $\lambda$, then the angle of reflection will be spread by $\pm 4 \pi \Delta h / \lambda$ as shown in Fig. 17. For a $30 \mathrm{~m}$ distance and a displacement of $\pm 0.25 \mathrm{~mm}$ at the target, which is about $10 \%$ of a typical capsule radius, we can tolerate a value of $\pm 0.066 \mu \mathrm{m}( \pm 660 \AA)$ for a wavelength of $100 \mathrm{~mm}$. This is a pointing accuracy of $\pm 8.3 \mu$ radians. The surface tension will be helpful in keeping surface disturbances small over short distances $<10 \mathrm{~mm}$. Over long distances $(>10 \mathrm{~mm}$ ) the backing plate must be kept flat to the parameters in Table 3.

Table 3

Surface disturbance allowed over the liquid metal mirror

\begin{tabular}{|l|l|}
\hline $\begin{array}{l}\text { Distance along } \\
\text { mirror, } \lambda, \mathrm{mm}\end{array}$ & Allowed perturbation, $\pm \Delta \mathrm{h}_{0}, \mu \mathrm{m}$ \\
\hline 1 & \pm 0.00066 \\
\hline 10 & $\pm 0.0066=6.6 \mathrm{~nm}=66 \AA$ \\
\hline 100 & $\pm 0.066=66 \mathrm{~nm} \sim \lambda_{\text {laser }} / 4$ \\
\hline $1000=1 \mathrm{~m}$ & \pm 0.66 \\
\hline $5,000=5 \mathrm{~m}$ & \pm 3.6 \\
\hline
\end{tabular}

The "polish" will have to be $< \pm 0.0066 \mu \mathrm{m}$ over distance of $<10 \mathrm{~mm}$ which is brought about by surface tension. Over distances of $10 \mathrm{~mm}$ or more the substrate polish must be $\pm 0.007 \mu \mathrm{m}$. Surface tension may relax this somewhat and should be the object of more analysis. We will assume the figure is twice this or $\pm 0.015 \mu \mathrm{m}$ when surface tension is fully included. We can use adaptive optics to hold the substrate to $\pm 0.66 \mu \mathrm{m}$ over $1 \mathrm{~m}$ distances. In summary, a substrate 
polish of $\pm 0.015 \mu \mathrm{m}( \pm 150 \AA$ or $\lambda / 20)$ with adaptive optics should meet the requirements to hit targets to within $\pm 0.25 \mathrm{~mm}$ (about $10 \%$ of the capsule radius) at $30 \mathrm{~m}$. To get a pointing accuracy of $\pm 25 \mu \mathrm{m}( \pm 0.83 \mu$ radians) should this become necessary would require a polish of the substrate of $\pm 0.0015 \mu \mathrm{m}( \pm 15 \AA)$. The diffraction limited spot size is about $9 \mu \mathrm{m}$.
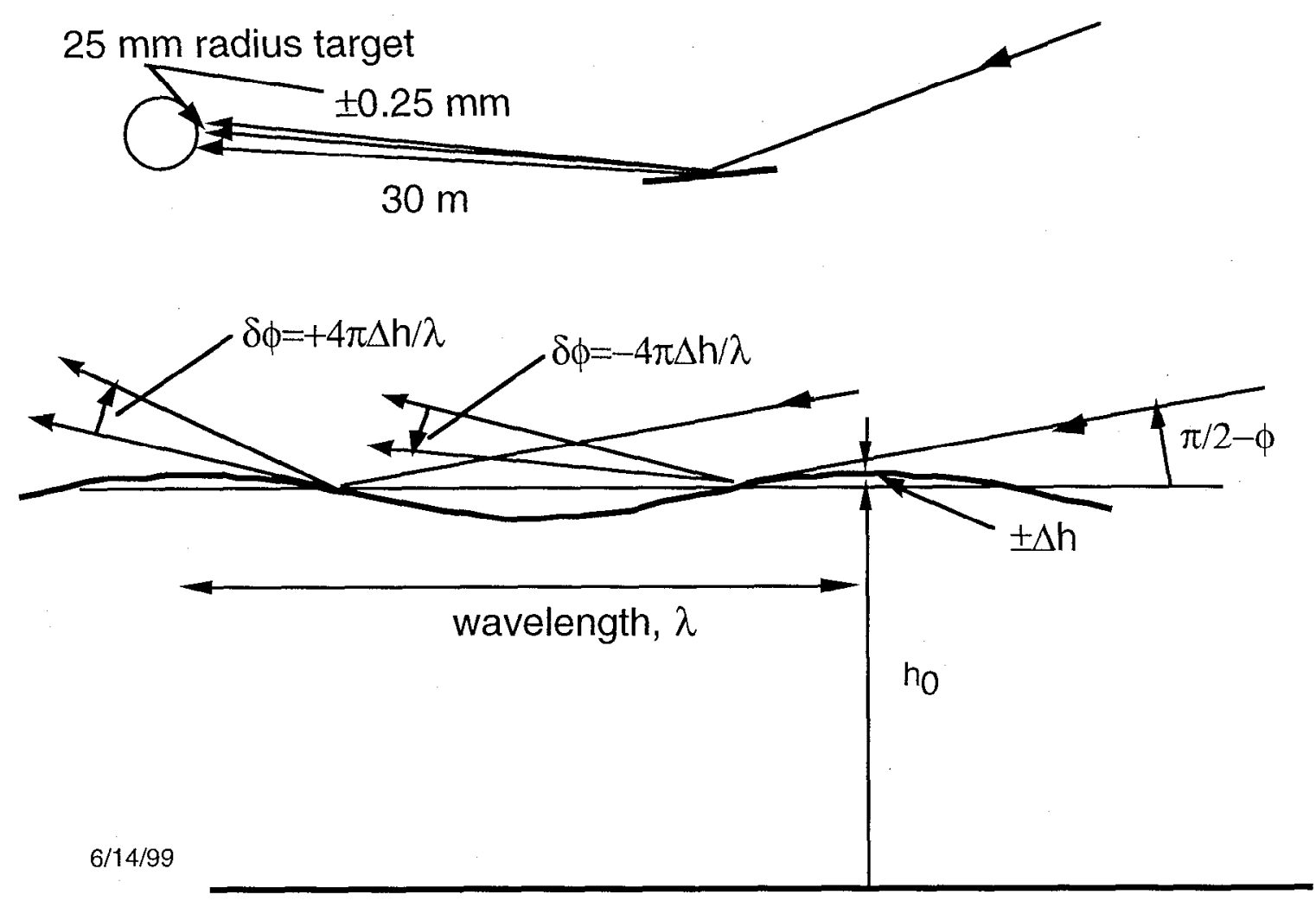

Fig. 17. A surface ripple on the liquid will cause a smear in the focal spot at the target by $\pm 4 \pi \Delta \mathrm{h} / \lambda$ in radians.

An experiment is needed to verify surface smoothness. It could be done with any liquid metal and any laser wavelength using the Reynolds number to extrapolate to other liquids. Another experiment is needed to verify the reflectivity at the high intensity shown in Table 1 . This experiment would be preferably done with $\mathrm{Na}$ and the correct optical wavelength so that no extrapolation by theory would 
be required assuming $\mathrm{Na}$ turns out to be preferred. Na seems to be favored at the present.

\section{Flow rate control}

Uniform flow rate will be important to keep the surface adequately smooth. The thickness varies with the third root of the flow rate as can be seen from Eq. 7. The flow rate for the $5^{\circ}$ slope case and $300 \mu \mathrm{m}$ is $8 \mathrm{~cm}^{3} / \mathrm{s}$ and for the $70^{\circ}$ slope case and $40 \mu \mathrm{m}$ film is $0.24 \mathrm{~cm}^{3} / \mathrm{s}$. A $\Delta \mathrm{h}$ of $\pm 0.6 \mu \mathrm{m}$ over a time of 36 seconds would be allowed from Table 2 for a surface wave length of $1 \mathrm{~m}$ down the slope of the mirror forcing the flow rate to vary by no more than $\pm 14 \%$ over $36 \mathrm{~s}$. The spatial feed at the top of the mirror must be uniform to within a flow rate of $\pm 7 \%$ over distances of $50 \mathrm{~cm}$ or so. Irregularities over $10 \mathrm{~cm}$ or less will be smoothed out by surface tension. The feed system requirements appear easily satisfied both spatially and over time.

\section{Meniscus effects}

The liquid can be constrained to flow down the slope and not over the edge by a lip of height higher than the meniscus height, $h$, or having an edge that does not wet.

$h=\left(\frac{T}{\rho g \cos \vartheta}\right)^{\frac{1}{2}} \cot \beta$

where $T$ is the surface tension, $\beta$ is the contact angle and $\theta$ the slope angle of flow. The lip needs to be only a few $\mathrm{mm}$ in most cases as can be seen from the Table 4 for the case of contact angle, $\beta$, equal to $45^{\circ}$. 
Table 4

Meniscus height

\begin{tabular}{|l|l|l|l|l|}
\hline Element & $\begin{array}{l}\text { surface tension, } \\
\mathrm{T}, \mathrm{N} / \mathrm{m}\end{array}$ & $\begin{array}{l}\text { density, } \\
\rho, \mathrm{kg} / \mathrm{m}^{3}\end{array}$ & $\begin{array}{l}\text { meniscus } \\
\text { heighth, } \mathrm{h}, \\
\mathrm{mm}, 5^{\circ} \text { slope }\end{array}$ & $\begin{array}{l}\text { meniscus } \\
\text { heighth, } \mathrm{mm} \\
70^{\circ} \text { slope }\end{array}$ \\
\hline $\mathrm{Al}$ & 0.52 & 2700 & 4.4 & 7.6 \\
\hline $\mathrm{Bi}$ & 0.37 & 9780 & 2.0 & 3.4 \\
\hline $\mathrm{Ga}$ & 0.735 & 5930 & 3.6 & 6.1 \\
\hline $\mathrm{In}$ & 0.34 & 7280 & 2.2 & 3.7 \\
\hline $\mathrm{Pb}$ & 0.438 & 11340 & 2.0 & 3.4 \\
\hline $\mathrm{Li}$ & 0.383 & 534 & 8.6 & 14.6 \\
\hline $\mathrm{Mg}$ & 0.563 & 1740 & 5.8 & 9.8 \\
\hline $\mathrm{Na}$ & 0.206 & 970 & 4.7 & 8.0 \\
\hline $\mathrm{Hg}$ & 0.465 & 14200 & 1.8 & 3.1 \\
\hline $\mathrm{K}$ & 0.086 & 870 & 3.2 & 5.4 \\
\hline Water & 0.073 & 1000 & 2.7 & 4.7 \\
\hline
\end{tabular}

Another effect of the meniscus is to distort the liquid surface near the edge of the mirror. The shape of the meniscus is

$y=h e^{-\left(\frac{g g \cos \vartheta}{T}\right)^{0.5} x}$

The slope of the surface is

$$
\frac{d y}{d x}=h\left(\frac{\rho g \cos \vartheta}{T}\right)^{0.5} e^{-\left(\frac{\rho g \cos \vartheta}{T}\right)^{0.5} x}
$$

which for $\beta=45^{\circ}$ is $e^{-\frac{x}{h}}$. The allowed deflection to still hit the target is estimated to be $\Delta \phi=0.25 \mathrm{~mm} / 30 \mathrm{~m}=8.3 \mu$ radians; $\mathrm{dy} / \mathrm{dx}=0.5 \Delta \phi$. This occurs for $\mathrm{x}=58$ and 99 $\mathrm{mm}$ for sodium at $5^{\circ}$ and $70^{\circ}$ slope. The wall to hold the liquid for an $85^{\circ}$ incident beam will obscure the edge of the mirror. For sodium this distance is $54 \mathrm{~mm}$ and $91 \mathrm{~mm}$.

Variation in surface tension and viscosity with temperature effects 
There is considerable analysis in the literature on the effects on flow of varying surface tension and viscosity with variations in temperature. These effects are more important for growth of waves but for our case where all waves are damped, the damping rate may changes somewhat but no new effects are expected. The temperature variation along and across the liquid film will drop to a low value during typical interpulse times $\left(0.035^{\circ} \mathrm{C}\right.$, see later section "Differential heating"). The fractional variation of surface tension and viscosity for sodium for a $0.035^{\circ} \mathrm{C}$ temperature change is $-1.73 \times 10^{-5}$ and $-1.6 \times 10^{-4}$ near $100^{\circ} \mathrm{C}$.

\section{Design of cooling system}

The cooling system must not introduce significant temperature variations along the film flow because changes in viscosity will change the flow rates and hence the thickness and result in a surface ripple. Analysis will be needed to see how much temperature variation can be allowed. If there is a temperature variation in the liquid metal film due for example to cooling channels in the back of the substrate as shown in Fig. 4, there will be a change in the viscosity and density. Lower viscosity will result in higher flow speed locally but due to continuity the flow rate is fixed so the film thickness will drop locally producing a ripple in the surface. The flow per unit length across the mirror $=$ feed rate $=$ constant $=2 \mathrm{Uh} / 3$ where $U$ is given in Eq. 9.

$$
\frac{\rho g h_{0}^{3} \sin \theta}{2 \eta}=\text { const }
$$

The variation in the film thickness, $h$, can be related to the variation in the ratio of viscosity to density.

$$
\frac{\Delta h}{h}=\frac{\Delta\left(\frac{\eta}{\rho}\right)}{3 \frac{\eta}{\rho}}
$$

From Table 3 we can allow $\Delta$ h to be $\pm 0.00667 \mu \mathrm{m}$ over distances of $10 \mathrm{~mm}$, which might be a typical coolant channel distance. For a $100 \mu \mathrm{m}$ thick film then $\Delta \mathrm{h} / \mathrm{h}<0.0066 / 100=0.66 \times 10^{-4}$ we then require $\Delta(\eta / \rho) / \eta / \rho<0.22 \times 10^{-4}$ 
From data on sodium we find $=9 \times 10^{-3}$ per degree

The allowed $\Delta \mathrm{T}<0.0024^{\circ} \mathrm{C}$ variation on the surface over distance of $10 \mathrm{~mm}$ and $0.024{ }^{\circ} \mathrm{C}$ over distance of $100 \mathrm{~mm}$.

In the section on differential heating we show the steady temperature rise of $0.002{ }^{\circ} \mathrm{C}$ is needed across a $100 \mu \mathrm{m}$ film to transmit $0.025 \mathrm{~J} / \mathrm{cm}^{2}$ absorbed at $6 \mathrm{~Hz}$. So we require the laser intensity does not vary by more than $100 \%$ over distances of $10 \mathrm{~mm}$ from shot to shot which seems easy to satisfy. The demands placed on the variation in the $\Delta T$ between the coolant channel and the film substrate to be no more than $\pm 0.002^{\circ} \mathrm{C}$ seems challenging. Clearly, the above discussion indicates thermal management will have to be taken seriously as a design parameter.

The effect of viscosity variation on stability of the flow has been studied by Goussis and Kelly ${ }^{14,15}$. They find an extra stabilizing effect for surface heating of the film and cooling from the back of the film as in our case.

\section{Vibration damping system}

The mirror system needs to be shock mounted and critically damped so that vibrations excited by, for example, bursts of vapor coming up the beam line (i.e., acoustic vibrations) at the microexplosion pulse rate of $6 \mathrm{~Hz}$ or so will damp by the next shot in $1 / 6 \mathrm{~s}$. It will be important to have such driving forces small and not be resonant with any natural frequencies that might set up a ripple pattern on the film. This means the natural frequency of all modes of the mirror must be greater than $6 \mathrm{~Hz}$. The isochoric heating of the liquid surface by the laser and by $x$ rays and the bulk liquid and substrate by neutrons are not expected to set up sustained vibrations because there is no net momentum transfer. As soon as the sound wave travels back and forth across the thickness of the mirror substrate of $10 \mathrm{~mm}$ or so a few times these vibrations damp out in times of tens of microseconds (several times the sound transit time). There are tens of thousands of transit times across the film and substrate combined. There will be internal reflections. The media will have damping in it. The support structure of the substrate will cause scattering of acoustic vibrations turning components into travel along the direction of the film flow with further damping. This subject can be analyzed further but looks likely to be no problem. 
If there is some ablation of liquid or vapor, then there would be net momentum transferred to the substrate and mounting system, however we design to avoid ablation. Another driving force would be acoustic coupling through gas. This motion would be easily critically damped in times short compared to the interpulse time of $\sim 1 / 6 \mathrm{~s}$ but still may set up standing waves on the liquid film. Therefore, we recommend keeping the gas at the mirror intentionally placed there to stop debris or from the debris itself at a very low pressure.

\section{Energy in vibrations}

From Table 1 for $\mathrm{Na}$ the laser energy incident on the liquid metal surface might be as high as $5 \mathrm{~J} / \mathrm{cm}^{2}$. The amount of laser light absorbed is $0.025 \mathrm{~J} / \mathrm{cm}^{2}$. The energy of vibration due to laser isochoric heating ( $24 \AA$ penetration, $80 \mathrm{~m} / \mathrm{s}$ vibration speed, an over estimate) is $0.8 \times 10^{-6} . \mathrm{J} / \mathrm{cm}^{2}$ and the kinetic energy in the flow for $100 \mu \mathrm{m}$ film and $10^{\circ}$ slope is $0.5 \times 10^{-9} \mathrm{~J} / \mathrm{cm}^{2}$. More study is called for of the dissipation of the vibration in the liquid caused by laser heating and possible coupling to surface disturbances not sufficiently damped as to disrupt good reflectivity. 


\section{Active pointing system}

Suppose the position of a target can accurately be injected to within a zone of \pm 10 $\mathrm{mm}$ and be predicted by telemetrics to an accuracy of less than $\pm 0.25 \mathrm{~mm}$. Can the GILMM at a distance of $30 \mathrm{~m}$ be turned by $10 \mathrm{~mm}$ or 0.3 mradians to an accuracy of $\pm 8.3 \mu$ radians $( \pm 0.25 \mathrm{~mm}$ ) in a time short compared to the interpulse time of $1 / 6 \mathrm{~s}$ for $6 \mathrm{~Hz}$ ? The forces on actuators needed to do this are modest ( $100 \mathrm{~N}$ or 20 pounds). The mounting of the GILMM must be critically damped and must have natural frequencies of vibration modes much faster than $6 \mathrm{~Hz}$. Therefore it seems the mirror can be actively pointed for each target if desired and if this motion does not excite surface disturbances on the film.

\section{Differential heating}

The $x$ rays and neutrons hit a distance in from the mirror edge as shown in Fig. 4., thus heating up and expanding that portion. This will tend to cause warpage which must be counter acted by the transducers. The warpage would be reduced if the $x$ rays and neutrons hit the entire mirror and then the substrate would be expected to heat uniformly. The draw back of not collimating, though, is the intense heating of surfaces of the support struts and less so of their volumes. While the temperature at the surface of the liquid will increase $200{ }^{\circ} \mathrm{C}$ at the end of the laser pulse in our examples, it returns to its steady value in $0.2 \mu \mathrm{s}$ of about $0.035^{\circ} \mathrm{C}$ above the temperature of the substrate for a $100 \mu \mathrm{m}$ film of $\mathrm{Na}$ for a laser beam of $5 \mathrm{~J} / \mathrm{cm}^{2}$ on the film $\left(0.025 \mathrm{~J} / \mathrm{cm}^{2}\right.$ absorbed $)$ or $57 \mathrm{~J} / \mathrm{cm}^{2}$ transverse to the beam and $6 \mathrm{~Hz}$. The steady temperature rise would only be $0.002{ }^{\circ} \mathrm{C}$ for the laser heating only, if the $x$ rays were absorbed some other way. Neutron heating has been neglected here.

\section{Dry out}

It is essential the liquid film wets the substrate. If the surface becomes dry in spots, rivulets will form and surface ablation of the substrate can be expected. A method to wet once dry out occurs, for example, by vapor deposition may be needed. Hoffman and Potts have studied the wetting problem for lithium ${ }^{16}$. 


\section{Neutron effects}

Over long periods of time swelling of the substrate is expected and differential swelling will lead to warpage. As in the above discussion, there would be much less warpage if the neutrons illuminated the entire mirror rather than be collimated and expose just a footprint on the liquid surface. If the surface varies due to radiation damage on a local scale over distance of 10 to $100 \mathrm{~mm}$ by more than $\pm 0.015 \mu \mathrm{m}$, then periodic resurfacing or replacement would be necessary because the film will also be distorted by a like amount. Over long distances ( $>100 \mathrm{~mm}$ ), neutron induced warpage can be accommodated by the slow adaptive optics system. Sawan and Khater ${ }^{17}$ estimate the flux of neutrons over $0.1 \mathrm{MeV}$ on the mirror is $8.2 \times 10^{12} \mathrm{n} \cdot \mathrm{cm}^{-2} \mathrm{~s}^{-1}$ and is due mostly to direct source neutrons. Over a 30 year period at $80 \%$ capacity factor this would result in a fluence of $6.2 \times 10^{21} \mathrm{n} / \mathrm{cm}^{2}$. More analysis is needed to prove the mirrors can last the life of the plant.

An extensive study of grazing incidence metal mirror (GIMM) was made by Bieri ${ }^{1}$. He estimated the damage threshold for Aluminum GIMM at a laser energy of $1.5 \mathrm{~J} / \mathrm{cm}^{2}$ on the mirror surface for $85^{\circ}$ from normal, which corresponds to $18 \mathrm{~J} / \mathrm{cm}^{2}$ normal to the beam. The lifetime of mirrors located at 30 $m$ was estimated to be 3 years for 1000 MWe based on the effects of neutron damage causing surface roughness. A critical issue with GIMM was the necessity to avoid surface defects, or keeping small objects $(>1 \mu \mathrm{m})$ such as dust from the surface because once appearing, the damage will grow and destroy the mirror. The damage mechanism is heat deposition causing the surface to exceed the elastic limit resulting in surface roughness. Further heat can cause melting and evaporation. These effects are cumulative. The lifetime of the GIMM will then be determined by the time for the first surface defect or debris to occur. Then the surface would need cleaning or repairing. Otherwise the mirror would then be useless. Frequent changeout of GIMM would be problematic in two ways. The cost of replacing the mirror and the down time in the replacement both have the effect of increasing the cost of electricity. Robotics will be necessary to quickly replace, locate, and align replacement mirrors. The liquid film added to the GIMM should extend the three year lifetime estimate perhaps to 30 years but just how long is left for further study. 


\section{X-ray effects}

Xenon gas may be needed to protect the chamber and optics from $x$ rays, and this, gas may be used in the beam tubes to stop debris. Without any gas protection, the burst of $x$ rays will cause surface heating independent of angles of incidence for the mirrors located $30 \mathrm{~m}$ from the microexplosion. This has been estimated and the results are given in Table 5 for $50 \mathrm{MJ}$ of $\mathrm{x}$ rays at $3 \mathrm{keV}$ and 10 $\mathrm{keV}$ to illustrate the problem. To do the problem correctly we need the $\mathrm{x}$-ray spectra, which for heavy ion targets is estimated ${ }^{18}$ to radiate as a black body at $350 \mathrm{eV}$. At energy depositions below the vapor ablation we still are concerned with isochoric pressure causing expansion and a liquid ablation when the tensile wave "breaks" or exceeds the tensile strength of the liquid. For Li there is no problem but for much heavier elements there is a problem because we expect $x$ ray intensities of $4.42 \mathrm{~kJ} / \mathrm{m}^{2}\left(0.44 \mathrm{~J} / \mathrm{cm}^{2}\right)$. The liquid at the surface finds itself under pressure due to the isochoric heating by $x$ rays. The surface expands at the "jump off" speed, which is defined as

$v_{\text {jumpoff }}=\frac{P_{o}}{\rho c}=\frac{\Gamma \mathrm{E}_{n}}{\rho c}$

where $E_{n}$ is the volumetric energy density, $c$ is the speed of sound, $\Gamma$ is the Gruneisen parameter.

Table 5

Temperature rise due to $\mathrm{x}$-ray burst

\begin{tabular}{|l|l|l|l|l|l|l|}
\hline Element & \multicolumn{5}{|l|}{ Temperature rise, $\mathrm{K}$} & \multicolumn{4}{l|}{ Isochoric } & \multicolumn{2}{l|}{ Jump off speed, } \\
& \multicolumn{2}{|l|}{$\begin{array}{l}\text { pressure, } \mathrm{GPa} \\
\mathrm{m} / \mathrm{s}\end{array}$} \\
& $3 \mathrm{keV} \quad 10 \mathrm{keV}$ & $3 \mathrm{keV}$ & $10 \mathrm{keV}$ & $3 \mathrm{keV}$ & \multicolumn{1}{l|}{$10 \mathrm{keV}$} \\
\hline $\mathrm{Li}$ & 0.5 & 0.04 & 0.002 & 0.0002 & 2.1 & 0.17 \\
\hline $\mathrm{Na}$ & 185 & 5 & 0.16 & 0.005 & 67 & 1.9 \\
\hline $\mathrm{Al}$ & 319 & 11 & 3.8 & 0.13 & 220 & 7.4 \\
\hline $\mathrm{Ga}$ & 983 & 37 & 2.3 & 0.09 & 196 & 7.3 \\
\hline $\mathrm{Pb}$ & 6300 & & 25 & & 1200 & \\
\hline $\mathrm{Hg}$ & 6600 & 380 & 13 & 0.7 & 610 & 35 \\
\hline
\end{tabular}


We need to know what pressure (which soon becomes tension) will result in liquid ablation or spall. It appears lithium will not spall, whereas Al likely will. Even if spall occurs, the surface will heal. Spall should be avoided or minimized but is not fatal. The above analysis should be redone for a calculated $\mathrm{x}$-ray spectra from a direct drive capsulc and from an indirect drive target and should use a hydro code calculation to determine the spall condition. The consequence of this analysis will be whether or not $x$-ray protection such as xenon gas will be needed.

\section{Debris protection}

The target debris and ablated liquid coming from the chamber that is directed towards the mirror before the shutter closes will constitute a surface contaminant on the liquid mirror if not stopped by the protective gas shown in Fig. 3. This should amount to about $1 \mu \mathrm{g} / \mathrm{cm}^{2}$ coming up the beam line at $30 \mathrm{~m}$ before the shutters close in $0.1 \mathrm{~ms}$ or $0.0004 \mu \mathrm{m} / \mathrm{shot}^{19}$ on the mirror and for 500 shots appropriate to film transit across a $2 \mathrm{~m}$ mirror before all liquid is replaced with new incoming liquid, $0.2 \mu \mathrm{m}$, which is less than a wavelength and less than the optical penetration depth as shown in Table 2 and therefore should cause no interference with the laser reflection. The problem here appears to be a long-term contamination of the liquid which sets the design requirement for clean up of the liquid. Impurity contaminates can be serious as they can segregate to the surface. Those systems are favored that have major contaminants sink as in lithium oxide or fluoride in lithium as opposed to lead oxides floating on lead for example. This contamination can be almost entirely avoided by flowing a dry clean inert gas in the beam tube to stop the debris from getting to the liquid metal surface. Suppose we assume ten times the density of xenon gas $\left(10 \mathrm{mg} / \mathrm{cm}^{2}\right)$ will effectively stop the $1 \mathrm{mg} / \mathrm{cm}^{2}$ of debris. This would be $4.6 \times 10^{13}$ atoms $/ \mathrm{cm}^{3}$ over $10 \mathrm{~m}$ or $12.9 \mathrm{mTorr} \cdot \mathrm{m}$. The density of this gas flow is so low that its effect on laser optical propagation is negligible. Experiments by Nilson et al. ${ }^{18}$, showed laser propagation through $\mathrm{Kr} \sim 10 \mathrm{mg} / \mathrm{cm}^{2}$ of 20 Torr.m over $\sim 10 \mathrm{~m}$ distance with turbulent distortion of the focal spot $<100 \mu \mathrm{m}$. 


\section{X-ray protection by gas}

A high $Z$ gas such as xenon can provide protection of optics from $x$ rays if needed. This same gas provides protection from vapor and small droplets and other debris as discussed previously. We can expect 1/e reduction of $1 \mathrm{keV} x$ rays with 0.14 Torr $\bullet \mathrm{m}$ of $\mathrm{Xe}\left(1.1 \times 10^{-4} \mathrm{~g} / \mathrm{cm}^{2}\right.$ or $\left.18.2 \mathrm{~Pa} \cdot \mathrm{m}\right)$. At $3 \mathrm{keV}$ this becomes 1.8 Torr $\cdot \mathrm{m}$ of $\mathrm{Xe}\left(1.4 \times 10^{-3} \mathrm{~g} / \mathrm{cm}^{2}\right.$ or $230 \mathrm{~Pa} \cdot \mathrm{m}$. Large debris is moving slowly and will be stopped by the rotating shutters. Lehmberg at NRL predicts problems of propagating intense light through xenon gas at $0.248 \mu \mathrm{m}$ but little problem at 0.3 $\mu \mathrm{m}$ and longer wavelength ${ }^{20}$. The problem arises from a two photon resonance in Xenon near $0.248 \mu \mathrm{m}$ causing a strong negative index of refraction change. The resonance is not so close in $\mathrm{Kr}$ as to be a problem. Other gases than Xenon can be considered. For the extra intense ignitor beams this needs examining and is still unresolved. There is a speculation that xenon can be introduced as a fog of droplets that passes over $90 \%$ of the laser light but by the time $x$ rays return, the fog has turned into a gas that attenuates the $x$ rays. The xenon gas must be fairly quiescent to avoid turbulence producing focal spot size problems. Experiments were carried out that give encouragement that xenon can be introduced without unduly enlarging or deflecting the spot size ${ }^{21}$ if special care is given to laminarizing the gas flow to reduce turbulent index of refraction dispersion. They got acceptable $(<100 \mu \mathrm{m})$ focal properties with 20 Torr $\bullet \mathrm{m}$ of gas, which will provide good protection from $x$ rays.

\section{Blast effect on mirror deflection and mitigation}

The gas blast from the micro explosion can be largely decoupled from the mirror, however, some vapor impulse can be tolerated. Isochoric heating by neutrons and $x$ rays do not impart net momentum, so, should not harm the focal properties. If ablation of liquid or vapor occurs there will be momentum imparted to the mirror. In either case the adaptive optics system with its spring mountings with transducers and dampers will be designed to have their natural frequencies higher than typical pulse rates of $\sim 6 \mathrm{~Hz}$ and be close to critically damped. The blast has been estimated by Jantzen ${ }^{17}$ to have an impulse of 30 Pa.s at $3 \mathrm{~m}$ for a $400 \mathrm{MJ}$ indirect drive heavy ion target. This impulse will diminish faster than $1 / \mathrm{r}^{2}$ especially with proper baffles. At $30 \mathrm{~m}$ an over estimate of the impulse would be 0.3 Pa.s. A mirror might have a mass of $140 \mathrm{~kg}$. A suspension 
system frequency of $60 \mathrm{~Hz}$ which would result in a negligible displacement of $5 \times 10^{-7} \mu \mathrm{m}$. For grazing incidence this would displace the focal spot by the same amount. The focal spot tolerance might be $\pm 250 \mu \mathrm{m}$. A Flibe droplet of $1 \mathrm{~mm}$ radius and speed of $1000 \mathrm{~m} / \mathrm{s}$ would cause an impulse over the mirror of 1.3 Pa.s.

\section{Optical alignment}

The optical elements and adaptive optical corrections will have to periodically be corrected. This can be done by injecting special targets which are intended for beam alignment and not energy production. One target out of every 200 would hardly be missed. Then just one or a few beams can be fired onto this target and the position of the spot and its shape can be measured and corrections made. By this means all beams can be upgraded periodically. For 60 beams it would take at most about 0.5 hours to update each beam once and much less if several were done at the same time. The optical system required for these observations will occupy ports and need to be radiation hardened, however, high intensity on the optical surface is not needed. Even ion driven IFE will need an optical observation system for alignment purposes.

\section{Experimental test apparatus}

The GILMM concept can be tested in relatively simple low cost apparatus that is then brought to an appropriate laser for testing. Initial test in a glove box may be appropriate. A low power steady laser can be used to test the smoothness of the flow by looking at its reflected focal spot. If the flow has waves, the focal spot will oscillate. A high power density $\left(57 \mathrm{~J} / \mathrm{cm}^{2}\right.$ over $20 \mathrm{~ns}$ or $2.9 \times 10^{9} \mathrm{~W} / \mathrm{cm}^{2}$ based on sodium from Table 1) laser can tesl deliverability of high power into a reflected focal spot. For a focal spot size of $>0.1 \mathrm{~mm}$, the laser should have $>4.9$ $\mathrm{mJ},>2.2 \times 10^{5} \mathrm{~W}$ for $20 \mathrm{~ns}$. A schematic of such a test facility is shown in Fig. 18. 


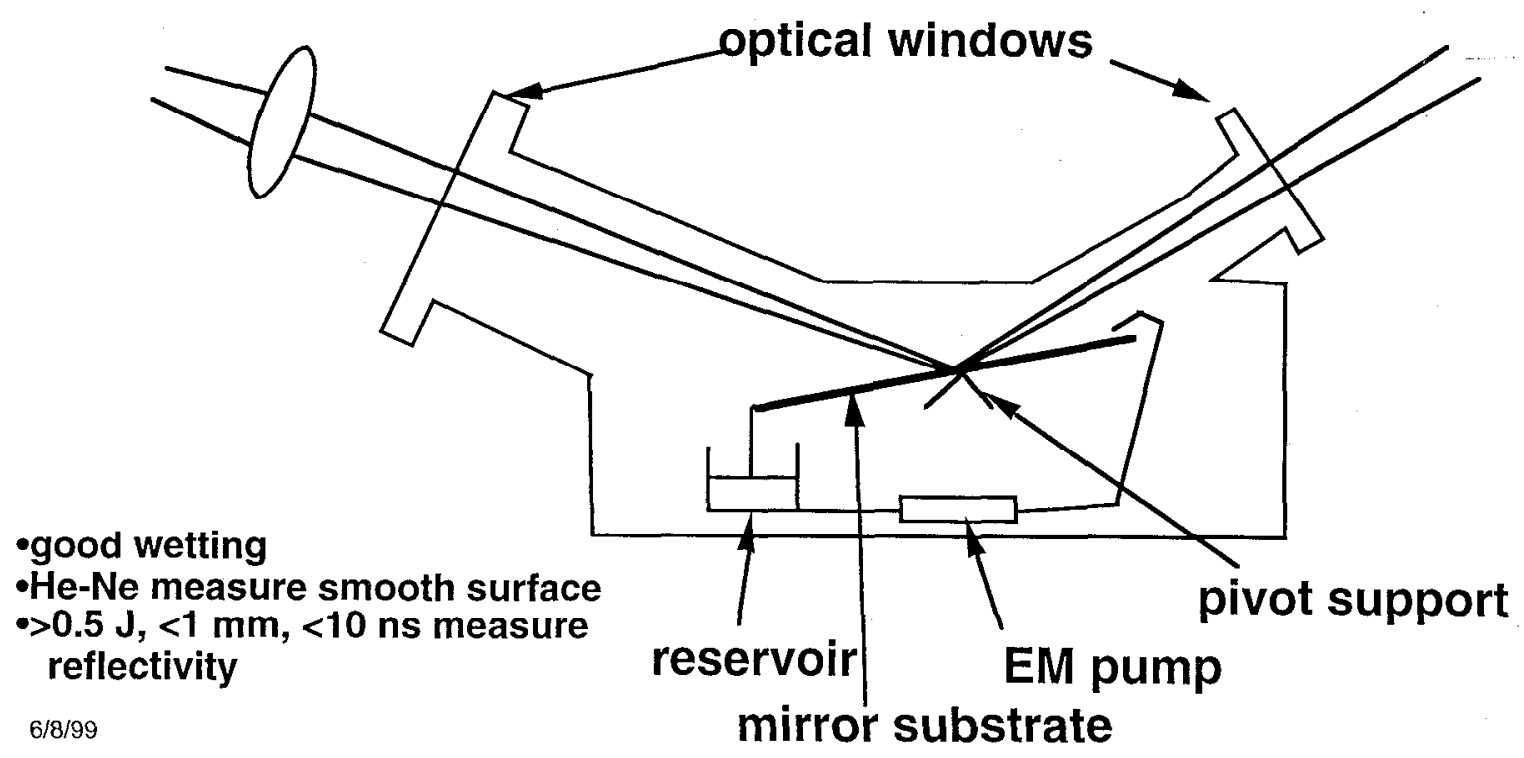

Fig. 18. Schematic of experiment to test the GILMM concept.

\section{Conclusion}

A thin liquid metal film of $\sim 100 \mu \mathrm{m}$ thickness flowing down an inclined plane can form a smooth surface for use as the final optical element for laser fusion. This reflective mirror should have long service life and can stand bursts of neutrons, dcbris and $x$ rays from fusion microexplosions. The next optical element being out of the direct line of sight of the microexplosions can use coated dielectric optics, diffractive optics, or what ever optics is in use in non radiation environments. The allowed intensity on the mirror at $85^{\circ}$ from normal incidence is predicted to be $9.3,5$, and $0.7 \mathrm{~J} / \mathrm{cm}^{2}$ for aluminum, sodium and lithium, which is 106,57 , and $7.7 \mathrm{~J} / \mathrm{cm}^{2}$ normal to the beam for aluminum, sodium and lithium. Environmental acoustic vibrations may present some problem because they can couple to standing waves on the film. Non uniform laser heating is not predicted to lead to ripples. More analysis will be needed to determine feasibility of the concept and to chose which liquid metal best meets the IFE requirements.

Experimental verification of the GILMM idea is recommended.

\section{Acknowledgments}

Discussions with M. Hoffman, Robert Kelley, N. Morley, S. Payne and A. Ying are appreciated. 


\section{References}

1. R. L. Bieri and M. W. Guinan, "Grazing Incidence Metal Mirrors as the Final Elements in a Laser Driver for Inertial Confinement Fusion," Fusion Technology 19 (1991) 673-678. Chapter 4 of Bieri's PhD thesis (which is cited in this paper) goes into more detail.

2. L. M. Waganer, "Innovation lead the way to attractive inertial fusion energy reactors-Prometheus-L and Prometheus-H," Fus. Eng. and Design 25 (1994) 125-143.

3. W. R. Meier, "Osiris and Sombrero inertial fusion power plant designs-summary, conclusion, and recommendations," Fusion Engineering and Design, 25, (1994) 145-157.

4. J. Hovingh, J. A. Maniscalco, M. Peterson, and R. W. Werner, “The preliminary design of a suppressed ablation laser induced fusion reactor," Proc. $1^{\text {st }}$ Topl. Mtg. Technology of Controlled Nuclear Fusion, San Diego, California, April 1618, 1974, CONF-740402, 1 (1974) 96.

5. J. K. Baird and V. E. Anderson, "Combination first wall and parabolic lithium mirror for a laser-driven pellet fusion reactor," Proc. $6^{\text {th }}$ Symp. Engineering Problems of Fusion Research, San Diego, California, November 17-21, 1975, CONF-751125, p. 1015 (1976).

6. P. Hickson, E. F. Borra, R. Cabana, R. Content, B. K. Gibson and G. A. Walker, "UCB/Laval 2.7 meter Liquid Mirror Telescope," Astrophy. J. Part II (1994).

7. C. D. Marshall, J. A. Speth, S. A. Payne, "Induced optical absorption in gamma, neutron and ultraviolet irradiated fused quartz and silica," J. of NonCrystalline Solids 212 (1997) 59-73.

8. C. D. Orth, "Interplanetary space transport using inertial fusion propulsion ," Proceedings of The Ninth International Conference on Emerging Nuclear Energy Systems (ICENES-9), Tel-Aviv, June 28-July 2, 1998, p 253-263.

9. R. Kingslake, Applied optics and optical engineering, Vol. III, p309 Academic Press, New York (1965).

10. A. T. Anderson, "X-ray ablation measurements and modeling for ICF applications," Lawrence Livermore National Laboratory report UCRL-LR125352 (1996). 
11. M. Tabak, J. Hammer, M. E. Glinsky, W. L. Kruer, S. C. Wilks, J. Woodworth, E. M. Campbell, M. D. Perry, "Ignition and high gain with ultrapowerful lasers," Phys. Plasmas 1 (1994) 1626-1634.

12. J. DeVan, Private communications, September, 1997.

13. J. E. Howard, "On the stability of the flow of thin liquid-lithium films,"

Nuclear Science and Engineering 69 (1979) 94-99.

14. D. Goussis and R. E. Kelly, "Effects of viscosity variation on the stability of film flow down heated or cooled inclined surfaces: long-wavelength analysis," Phys. Fluids 28 (1995) 3207-3214.

15. D. Goussis and R. E. Kelly, "Effects of viscosity variation on the stability of film flow down heated or cooled inclined surfaces: finite-wavelength analysis," Phys. Fluids 30 (1997) 974-982.

16. M. A. Hoffman and W.W. Potts, "Experimental behavior of falling liquid films at high surface tension numbers," Ind. Eng. Chem. Fundam. 18 (1979) 2717. M. E. Sawan H. Y. Khater, "Nuclear analysis for the blanket and shield of the KrF laser driven inertial fusion reactor 'SOMBRERO," Proceedings of the $15^{\text {th }}$ IEEE Symposium on Fusion Enginecring, Oct 11-15, 1993, Hyannis, Mass (1994) 769-772.

18. Max Tabak via Caron Jantzen, private communication, 8/98.

19. Caron Jantzen, UC Berkeley, private communication, 1997.

20. R. Lehmberg, unpublished NRL work and private communication, June 6 , 1997 and R. H. Lehmberg, Optics Communications 121 (1995) 78-88.

Unpublished experimental results are available (1999).

21. D. Nilson, W. G. Unites, C. E. Hackett, and W. E. Jorgenson, "Laser Driven ICF Beam Propagation Through Protective Gas-Puffs," unpublished Lawrence Livermore National Laboratory report March 15, 1990. 